\title{
Crosstalk Between Dysfunctional Mitochondria and Inflammation in Glaucomatous Neurodegeneration
}

\author{
Assraa Hassan Jassim ${ }^{1}$, Denise M. Inman ${ }^{2}$ and Claire H. Mitchell ${ }^{1,3,4 *}$ \\ ${ }^{1}$ Department of Basic and Translational Science, University of Pennsylvania, Philadelphia, PA, United States, ${ }^{2}$ Department of \\ Pharmaceutical Sciences, North Texas Eye Research Institute, University of North Texas Health Science Center, Fort Worth, TX, \\ United States, ${ }^{3}$ Department of Ophthalmology, University of Pennsylvania, Philadelphia, PA, United States, ${ }^{4}$ Department of \\ Physiology, University of Pennsylvania, Philadelphia, PA, United States
}

OPEN ACCESS

Edited by: Claudio Bucolo, University of Catania, Italy

Reviewed by:

Chiara Bianca Maria Platania, University of Catania, Italy Julie Sanderson,

University of East Anglia, United Kingdom

*Correspondence: Claire H. Mitchell chm@upenn.edu

Specialty section: This article was submitted to Experimental Pharmacology and Drug

Discovery,

a section of the journal Frontiers in Pharmacology

Received: 23 April 2021 Accepted: 22 June 2021

Published: 21 July 2021

Citation:

Jassim AH, Inman DM and Mitchell $\mathrm{CH}$

(2021) Crosstalk Between

Dysfunctional Mitochondria and Inflammation in

Glaucomatous Neurodegeneration.

Front. Pharmacol. 12:699623.

doi: 10.3389/fphar.2021.699623
Mitochondrial dysfunction and excessive inflammatory responses are both sufficient to induce pathology in age-dependent neurodegenerations. However, emerging evidence indicates crosstalk between damaged mitochondrial and inflammatory signaling can exacerbate issues in chronic neurodegenerations. This review discusses evidence for the interaction between mitochondrial damage and inflammation, with a focus on glaucomatous neurodegeneration, and proposes that positive feedback resulting from this crosstalk drives pathology. Mitochondrial dysfunction exacerbates inflammatory signaling in multiple ways. Damaged mitochondrial DNA is a damage-associated molecular pattern, which activates the NLRP3 inflammasome; priming and activation of the NLRP3 inflammasome, and the resulting liberation of IL-1 $\beta$ and IL-18 via the gasdermin $\mathrm{D}$ pore, is a major pathway to enhance inflammatory responses. The rise in reactive oxygen species induced by mitochondrial damage also activates inflammatory pathways, while blockage of Complex enzymes is sufficient to increase inflammatory signaling. Impaired mitophagy contributes to inflammation as the inability to turnover mitochondria in a timely manner increases levels of ROS and damaged mtDNA, with the latter likely to stimulate the cGAS-STING pathway to increase interferon signaling. Mitochondrial associated ER membrane contacts and the mitochondria-associated adaptor molecule MAVS can activate NLRP3 inflammasome signaling. In addition to dysfunctional mitochondria increasing inflammation, the corollary also occurs, with inflammation reducing mitochondrial function and ATP production; the resulting downward spiral accelerates degeneration. Evidence from several preclinical models including the DBA/2J mouse, microbead injection and transient elevation of IOP, in addition to patient data, implicates both mitochondrial damage and inflammation in glaucomatous neurodegeneration. The pressure-dependent hypoxia and the resulting metabolic vulnerability is associated with mitochondrial damage and $\mathrm{L}-1 \beta$ release. Links between mitochondrial dysfunction and inflammation can occur in retinal ganglion cells, microglia cells and astrocytes. In summary, crosstalk between damaged mitochondria and increased inflammatory signaling enhances pathology in glaucomatous neurodegeneration, with implications for other complex age-dependent neurodegenerations like Alzheimer's and Parkinson's disease.

Keywords: retinal ganglion cells, mitophagy, microglia, glaucoma, NLRP3 infammasome, astrocyte, metabolic vulnerability 


\section{GLAUCOMATOUS NEURODEGENERATION}

Glaucoma is a neurodegenerative disease that can ultimately lead to irreversible blindness (Tham et al., 2014). This etiologically complex optic neuropathy is characterized by progressive structural and functional loss of retinal ganglion cells (RGCs). Pathology is found in RGC compartments; the soma in the inner retina, the axons which form the core component of the optic nerve head $(\mathrm{ONH})$ and the optic nerve $(\mathrm{ON})$ relaying visual information to the brain. The retina, $\mathrm{ONH}, \mathrm{ON}$, and brain regions respond differently in glaucoma, giving rise to compartmentalized degeneration (Tamm et al., 2017). Accordingly, RGCs can execute autonomous degeneration to eliminate different parts of themselves upon insult, including the dendrites and soma within the retina itself, the axons passing through the $\mathrm{ONH}$ and $\mathrm{ON}$, and the synapses within the brain (Whitmore et al., 2005).

Many forms of glaucoma are associated with elevated intraocular pressure (IOP). While lowering IOP is currently the primary therapy available to slow down glaucoma pathology, it does not necessarily prevent blindness, and glaucomatous neurodegeneration extends beyond IOP elevation into complex cellular pathologies. The moderate elevations in IOP associated with most common forms of glaucoma, with IOP values $21-30 \mathrm{mmHg}$, are largely asymptomatic, resulting in a delayed glaucoma diagnosis, which in turn defers therapy initiation until after RGC death has begun. Normal tension glaucoma (NTG) can occur in individuals with IOP in the normal range of $15-20 \mathrm{mmHg}$; however, patients still benefit from lowering IOP suggesting a differential pressure sensitivity to IOP among individuals (Josef et al., 2002; Whitmore et al., 2005; Calkins, 2012). Regardless of IOP levels, glaucomatous neurodegeneration involves a complex interaction between multiple factions including age, genetics, mechanical strain, hypoxia, neurochemical signaling, autophagy, cellular energetics and immune signals. In this review, we will discuss the crosstalk between mitochondrial dysfunction and inflammation during glaucoma.

\section{MODELS OF GLAUCOMATOUS NEURODEGENERATION}

Molecular mechanisms of glaucoma differ from person to person and across animal models (Fernandes et al., 2015; De Moraes et al., 2017; Pang and Clark, 2020). All models require certain compromises, there is no "perfect" model of glaucoma and thus comparing results from multiple models provides a better understanding of glaucoma pathology. As rodent models facilitate large-scale studies and genetic manipulations, they offer convenience as model systems.

The DBA/2J (D2) mouse is a well-established model of inherited glaucoma (Libby et al., 2005). IOP elevation is secondary to excessive iris pigment dispersion, which consequently blocks the trabecular meshwork and drives aqueous humor accumulation, thereby causing IOP elevation. This iris disease is linked to recessive mutations in tyrosinaserelated protein 1 (Tyrp1) and glycoprotein nonmetastatic melanoma B (Gpnmb). These mutations induce melanogenesis toxicity and a subsequent inflammatory response directed at the iris, which forms structural melanosome abnormalities seen in both humans and D2 mice. IOP elevation in D2 mice is spontaneous and progressive, starting at 6 months (14-18 $\mathrm{mmHg}$ ) and leveling off by 11 months at a value of about $28 \mathrm{mmHg}$ (Mahesh et al., 2007).

Ocular hypertension (OHT) can also be induced in animal models through a variety of surgical interventions to impede aqueous outflow to some extent and hence elevate IOP. Transient IOP elevations are produced by cannulating the anterior chamber of the eye, while more sustained elevations in IOP can be produced following hypertonic saline injection into the episcleral vein, microbead injection into the anterior chamber of the eye, translimbal laser photocoagulation, or cauterization of episcleral veins. The microbead model offers advantages in the mouse given its flexibility and consistency that allows relative ease of use (Sappington et al., 2010; Samsel et al., 2011; Yang et al., 2012), although the best choice is based on the specific experimental questions being addressed. IOP can also be elevated following steroid application (Whitlock et al., 2010; Overby and Clark, 2015); systemic administration of dexamethasone has been used to demonstrate the role of dopamine and serotonin in IOP regulation (Bucolo et al., 2012; Platania et al., 2013), and has even been used to raise IOP in cows (Gerometta et al., 2004). The combined use of multiple models to confirm a specific outcome is preferable given the inherent compromises with each.

\section{MITOCHONDRIAL DYSFUNCTION IN GLAUCOMA}

Mitochondrial dysfunction has been strongly implicated in glaucomatous neurodegeneration in patients and multiple models of glaucoma (Kong et al., 2009; Munemasa et al., 2010; Lee et al., 2011; Kamel et al., 2017). Neurons are particularly sensitive to mitochondrial challenge as they require high levels of energy to maintain the electrochemical gradients necessary for optimal signal transmission, and ATP is the primary source of this energy. ATP is produced by mitochondria through oxidative phosphorylation of the electron transport chain and glycolysis (Frenzel et al., 2010). Neurons are particularly dependent on mitochondrial ATP as they have reduced levels of 6phosphofructo-2-kinase/fructose-2, 6-bisphosphatase-3 activity (Pfkfb3), resulting in the shunting of glucose into the pentosephosphate pathway at the expense of glycolysis (Herrero-Mendez et al., 2009; Bolanos et al., 2010). Levels of ATP were reduced in optic nerves of 6 month old D2 mice in proportion to IOP elevation, and the ability of the compound action potential to recover after oxygen-glucose deprivation was worse in mice with higher IOP levels, suggesting the rate of ATP generation was reduced in these mice to the level where it interfered with transmission of the visual signal along the optic nerve (Baltan 
et al., 2010). This sensitivity occurred before changes in axon structure (Inman et al., 2006) or anterograde transport were detected (Dengler-Crish et al., 2014). Mitochondrial remodeling was found early in humans with glaucoma (Tribble et al., 2019) and the D2 glaucoma model (CwermanThibault et al., 2017). Rat RGCs showed a sustained decrease in ATP production with IOP elevation that was maintained after IOP levels returned to baseline (Wu et al., 2015). These observations support the theory that mitochondrial dysfunction and ATP reduction are among the first changes that occur following IOP elevation and may be maintained.

In addition to reducing ATP levels, mitochondrial dysfunction also leads to increased generation of reactive oxygen species (ROS), and oxidative stress. Reduced cytochrome c oxidase (Complex IV) activity generates dysfunctional mitochondria, which in turn induces ROS production from the endoplasmic reticulum (ER) (Leadsham et al., 2013; Murphy, 2013). Consequently, the accumulation of dysfunctional mitochondria induces non-physiological ROS production, and the resulting oxidative stress can induce glaucomatous damage (Nita and Grzybowski, 2016). Mitochondrial dysfunction also drives the release of cytochrome $\mathrm{c}$; while cytochrome $\mathrm{c}$ is normally involved in the electron transport chain, it can initiate a caspase protease cascade during apoptosis (Chandra et al., 2002; Calkins, 2012). Although apoptosis contributes to RGC degeneration in glaucoma, inhibition of apoptosis is not sufficient to prevent optic neuropathy (Libby et al., 2005). Overall, mitochondrial dysfunction contributes to glaucomatous neurodegeneration by decreasing levels of ATP, increasing ROS generation through reduced Complex IV generation, and defective pathogenesis.

\section{HYPOXIA CONTRIBUTES TO MITOCHONDRIAL DYSFUNCTION}

IOP elevation exerts a mechanical stretch injury and strain to the tissues of the $\mathrm{ONH}$, pressing the central retinal artery as it passes through the $\mathrm{ONH}$; the subsequent impairment of ocular blood flow reduces the oxygen supply to the retina and induces a localized hypoxia (Josef et al., 2002; Dai et al., 2012; Stowell et al., 2017). As oxidative phosphorylation is dependent on oxygen, prolonged hypoxia results in decreased mitochondrial ATP production. During intermittent hypoxia, the cell can switch from oxidative phosphorylation to glycolysis until oxygen level returns to normal; RGCs exposed to intermittent hypoxia are thus protected from degeneration in ischemic preconditioning (Gidday et al., 2015). In prolonged hypoxia, however, glycolysis is insufficient to meet the high energy demand of neurons. Hypoxia stimulates superoxide generation from Complex III of the electron transport chain. Superoxide is converted to $\mathrm{H}_{2} \mathrm{O}_{2}$ by superoxide dismutase, triggering hypoxia-inducible factor $1 \alpha$ (HIF-1 $\alpha)$ stabilization and upregulation (Chandel et al., 1998; Chandel et al., 2000; Hamanaka and Chandel, 2009). Under physiological conditions, hypoxia is resolved by relief of oxidative stress, a metabolic switch to glycolysis, and removal of damaged mitochondria through mitophagy (Wu et al., 2016). However, prolonged hypoxia during glaucoma introduces dysfunctional feedback, impairing mitophagic induction and amplifying the accumulation of dysfunctional mitochondria that result in exacerbated oxidative stress and inflammation. Evidence exists for hypoxia at early stages of glaucoma in the D2 and microbead models (Jassim et al., 2021), and for oxidative stress (Jassim and Inman, 2019), mitochondrial dysfunction and limited mitophagy (Coughlin et al., 2015; Kleesattel et al., 2015) in glaucoma models.

Metabolic vulnerability also contributes to glaucomatous degeneration (Inman and Harun-or-Rashid, 2017; Williams et al., 2017; Harun-or-Rashid et al., 2018; Harun-or-Rashid et al., 2020). Axons rely primarily on glycolysis during glaucoma to compensate for mitochondrial dysfunction, though glycolysis is ultimately insufficient to rescue metabolic vulnerability associated with glaucoma (Jassim et al., 2021). Interestingly, the increased oxidative phosphorylation accompanying a ketogenic diet rescued RGC degeneration due, at least in part, to a reduction in inflammation (Harun-or-Rashid and Inman, 2018).

\section{INFLAMMATION IN GLAUCOMA}

Inflammation is now recognized as a key component of glaucoma neurodegeneration, and increased inflammatory signaling is one of the first changes detected in glaucoma. Activation of localized innate inflammatory signaling is of particular relevance in glaucoma, with involvement of cytokines and complement pathways clearly demonstrated at multiple stages of disease progression (Tezel, 2011; Rieck, 2013; Mac Nair and Nickells, 2015; Kamat et al., 2016; Russo et al., 2016; Bell et al., 2018). The elevated IOP in neovascular glaucoma is associated with high levels of vascular endothelial growth factor (VEGF), and antiVEGF compounds are used for treatment (Platania et al., 2015; Slabaugh and Salim, 2017). Pro-inflammatory cytokine signaling is also evident in the models; for example, signs of inflammation are present throughout RGC compartments in D2 mice early, change with age, and drive glaucoma in the absence of elevated IOP (Wax et al., 2008; Bosco et al., 2011; Bosco et al., 2015; Wilson et al., 2015). Blocking inflammatory responses has shown promise in ameliorating glaucoma in models (Bosco et al., 2008; Howell et al., 2011; Bosco et al., 2012; Yang et al., 2016; Panchal et al., 2017; Harun-or-Rashid and Inman, 2018), emphasizing the negative impact of inflammation. Induced models of ocular hypertension and optic nerve crush models have also demonstrated inflammation (Morzaev et al., 2015), while inflammation was reported within $4-6 \mathrm{~h}$ in the retina after transient IOP elevation (Albalawi et al., 2017; Pronin et al., 2019). RGCs showed mechanosensitive release of multiple cytokines (Lim et al., 2016), while optic nerve head astrocytes showed rapid upregulation and release of IL-6 in response to IOP elevation ( $\mathrm{Lu}$ et al., 2017). Glaucomatous human eyes and aqueous humor had increased markers for inflammatory cytokines and TNFa (Yang et al., 2011; Takai et al., 2012; Wang et al., 2018).

The NOD-, LRR- and pyrin domain-containing protein 3 (NLRP3) inflammasome is particularly important to 
inflammatory signaling in glaucoma (Yerramothu et al., 2018). Inflammasomes are multiprotein complexes that can release proinflammatory cytokines and are members of Nod-Like Receptor (NLR) or pyrin and HIN domain-containing families (Guo et al., 2015). NLRs are encoded by 23 genes, but only NLRP1, NLRP2, NLRP3, NLRP6, NLRP12, and NLRC4 are capable of forming oligomeric complexes that can activate caspase-1 (CASP1) (Zheng et al., 2020). Inflammasome complexes are composed of cytosolic pattern recognition receptors (PRRs), CASP1, NLRP, and the adaptor protein apoptosis-associated speck-like protein containing a caspase activation and recruitment domain (ASP) (Swanson et al., 2019). The NLRP3 inflammasome is the most widely studied within a glaucoma context, and involvement involves both priming and activation steps. Inflammasome priming occurs through the activation of NFKB signaling (Jo et al., 2016); expression of inflammasome components is low under baseline conditions, and priming to increase expression is necessary for a response. The second step involving assembly and activation of the complex occurs in response to a stressful event; ASC fibrils are recruited and activate CASP1; the accumulation of detectable ASC clusters is a marker for inflammasome activation (Venegas et al., 2017). Activated CASP1 mediates the cleavage of IL- $1 \beta$ and IL-18 into releaseable forms that exit cells through gasdermin D (GSDMD), and in some cases triggering inflammatory cell death through pyroptosis (Liu et al., 2016).

Damage-associated molecular patterns (DAMPs) and pathogen-associated molecular patterns (PAMPs) are common triggers of inflammasome activation (Jo et al., 2016) and DAMPs, such as extracellular ATP and ROS can be released following cell damage (Yin et al., 2016). Extracellular ATP is a widespread mechanism to activate the NLRP3 inflammasome (Couillin et al., 2013), and ATP release is frequently triggered by mechanosensitive changes in tissues, thus providing a potential link between mechanical strain and inflammation (Ventura et al., 2019). This has particular relevance for glaucoma as ATP was elevated in the aqueous humor of humans with acute (Zhang et al., 2007) and chronic angle-closure glaucoma (Li et al., 2011). Increased levels of extracellular ATP accompanied the sustained elevation of IOP in rats following injection of hypertonic saline into episcleral veins, the Tg-MYOCY437H transgenic mouse model, and primates subjected to the laser photocoagulation of the trabecular meshwork (Lu et al., 2015). ATP release was induced from bovine retinal eyecups by elevated pressure (Reigada et al., 2008), and from ONH astrocytes subjected to moderate cyclic strain (Beckel et al., 2014). Under normal conditions, extracellular ATP is rapidly degraded by the ectonucleotidases (Reigada et al., 2005; Allard et al., 2017), but the involvement of ATP in glaucomatous RGC loss suggests that release levels can overwhelm this degradation in some cases (Sanderson et al., 2014).

A role for NLRP3 inflammasome involvement in the loss of RGCs associated with elevated IOP has been demonstrated by multiple groups. Intravitreal injection of ATP triggered significant IL-1 $\beta$ release and ASC speck induction in RGCs and astrocytes, supporting the detrimental effects of extracellular ATP in inflammasome activation (Pronin et al., 2019). Acute activation of NLRP1/NLRP3, CASP1, and IL-1 $\beta$ in mouse RGCs, astrocytes, and Müller glia was detected within $6 \mathrm{~h}$ of transient elevation IOP to $120 \mathrm{mmHg}$, with activation peaking after $12-24 \mathrm{~h}$. Simultaneously, the pyroptotic pore was induced in the ganglion cell layer (GCL) and inner nuclear layer (INL) (Pronin et al., 2019). RGC degeneration was reduced in CASP1/CASP4 knockout (KO) and Panx1 KO mice, and by inhibition of pannexin, suggesting Panxl activates the inflammasome following ATP release from ischemically or mechanically stressed cells. In a separate study, production of IL-1 $\beta$ following IOP elevation to $110 \mathrm{mmHg}$ for $60 \mathrm{~min}$ was attributed to CASP 8 and the NLRP1/NLRP3 inflammasome (Chi et al., 2014). ASC, CASP1, and IL-1 $\beta$ rose in the retina following partial optic nerve crush, while RGC survival was greater when crush was performed in NLRP3 KO mice as compared to control (Puyang et al., 2016). ASC specks were increased in capillaries of contralateral normotensive eyes (Pronin et al., 2019) in addition to the hypertensive eyes; this may relate activated microglia in contralateral normotensive eyes (Rojas et al., 2014).

\section{GLIA CONTRIBUTE TO INFLAMMATORY RESPONSES IN GLAUCOMA}

Astrocytes, microglia, and Müller cells are the three major types of retinal glial cells, with the contribution by astrocytes and microglia particularly relevant to inflammation found with glaucoma (Wei et al., 2019; García-Bermúdez et al., 2021). Microglia are innate immune cells residing throughout the retina, $\mathrm{ON}$, and brain. Microglia act as sensors and are one of the first responders following CNS injury, undergoing rapid morphologic and molecular changes as they become "activated" (Lannes et al., 2017). Some forms of activated microglia have beneficial actions, such as increased phagocytosis of toxic debris and release of anti-inflammatory signals (Chen and Trapp, 2016). However, microglia are a key source of inflammatory signals, with prolonged injury leading to excess production of pro-inflammatory cytokines and neurotoxic factors such as IL-6, Tumor necrotic factor-alpha (TNFa), NO, and superoxide (Rodríguez-Gómez et al., 2020). The microglia pro-inflammatory response is coupled with a decrease of the antiinflammatory cytokine IL-10 during neurodegeneration that aggravates inflammation (Hickman et al., 2008; Heneka et al., 2013).

Reactive microglia have been localized to the retina and $\mathrm{ON}$ in multiple glaucoma models, and in human glaucoma (Yuan and Neufeld, 2001; Bosco et al., 2008). Microglial activation is detected in 3 month old D2 mice (Bosco et al., 2011; Bosco et al., 2012), and is predictive of subsequent neurodegeneration (Bosco et al., 2015). Early astrocyte reactivity and microglia activation were shown in the $\mathrm{ON}$ of D2 mice, and in rats with OHT following Translimbal Laser Photocoagulation (Son et al., 2010). Early microglial activation, $\mathrm{NF}-\kappa \mathrm{B}$ signaling, and neuroinflammation in the $\mathrm{ONH}$ were also reported in a cat genetic glaucoma model (Oikawa et al., 2020). Minocycline treatment and irradiation inhibited microglial activation and reduced RGC death in D2 mice (Bosco et al., 
2008; Bosco et al., 2012), supporting a negative impact of activated microglia on glaucoma progression. Recently, activated microglia were shown to induce reactive neurotoxic astrocytes by the release of interleukin-1 alpha (IL-1a), TNFa, and the classical complement component (C1q), and consequently drive RGC degeneration in the microbead glaucoma model (Liddelow et al., 2017; Guttenplan et al., 2020). Collectively, these studies provide strong evidence of the detrimental impact of activated microglia in glaucoma.

Glia-neuron interaction is emerging as a critical factor in neurodegeneration, and the pivotal role of ATP and purinergic signaling links cellular energetics to this interaction. Microglia constantly regulate and influence neurons via specialized somatic junctions (Madry et al., 2018; Cserep et al., 2020). ATP leakage from injured cells, through mechanosensitive channels, or from neuronal mitochondria through vesicular nucleotide transporter (vNUT) channels enriched at microglia-neuron contact sites is sensed by $\mathrm{P} 2 \mathrm{Y} 12$ receptors on microglia, triggering process extension and migration toward the injured sites (Koizumi et al., 2013; Cserep et al., 2020). Whether P2Y12 receptors play a direct role in microglial surveillance, or potentiate the activity of THIK-1 potassium channels as recently suggested (Madry et al., 2018), P2Y12 receptor stimulation by ATP clearly contributes to surveillance. Stimulation of the P2X7 receptor has also been implicated in microglial phagocytosis and degradation (Campagno and Mitchell, 2021), an effect which may have particular impact in aging cells. Inhibition of the $\mathrm{P} 2 \mathrm{X} 7$ receptor was shown to reduce microglia activation in D2 mice (Romano et al., 2020), suggesting a key role for the receptor in the inflammatory response in glaucoma. The P2X7 receptor also induces a rise in ROS (Bartlett et al., 2013; Munoz et al., 2017); whether this provides a pathway to link mitochondria with inflammation in glaucoma remains to be determined.

Optic nerve head astrocytes are also implicated in the link between mechanical strain and inflammation. Stretch and swelling of $\mathrm{ONH}$ astrocytes led to the release of ATP through pannexin hemichannels (Beckel et al., 2014). Stimulation of this released ATP through pannexins was implicated in the priming of the NLRP3 inflammasome, with increased expression of IL-1 $\beta$, NLRP3 and caspase1 (Albalawi et al., 2017). Transient elevation of IOP led to a similar priming and release of IL- 6 from optic nerve head astrocytes as well as ganglion cells (Lu et al., 2017).

Signaling from neurons back to glia also contributes to the link between mitochondrial dysfunction and inflammation in glaucoma. For example, fragmented and damaged mitochondria are found in activated microglia as a result of increased mitochondrial fission (Joshi et al., 2019). These damaged mitochondria are released into extracellular space, inducing an innate immune response by targeting adjacent astrocytes can also release dysfunctional mitochondria (Joshi et al., 2019). The resulting positive feedback can accelerate neuroinflammation. Inhibiting mitochondrial fission with heptapeptide P110, which inhibits binding of Drp1 to the mitochondrial receptor Fis1, reduced fragmentation and mitochondrial release from microglia, lessened astrocyte activation, and protected neurons from innate immune attack. Extracellular mitochondria can also signal between glia and neurons; functional mitochondria were found to be protective, while damaged mitochondria communicated pathology following stroke (Hayakawa et al., 2016). This suggests that the health of released mitochondrial may influence pathology in glaucoma.

Astrocytes are generally considered to protect neurons from oxidative stress, specifically via glutathione precursor synthesis, as they have strong antioxidant defenses regulated by the transcription factor Nrf2, a master regulator of redox homeostasis (Shih et al., 2003; Himori et al., 2013; Ghosh et al., 2020). However, reactive astrocytes contribute to neuronal degeneration in mice with sustained IOP elevation and reduction of their activated status rescued neuronal function (Guttenplan et al., 2020; Sterling et al., 2020). The decline in astrocytic antioxidant defense mechanisms and the increase in astrocytic reactivity during glaucoma occur simultaneously with mitochondria dysfunction, contributing to ROS accumulation and oxidative stress that enhance glaucoma progression (Tezel, 2006; Jassim and Inman, 2019). Intravitreal injection of neurotoxic astrocytes did not induce RGC neurodegeneration in the absence of neuronal injury, suggesting that injury and glial activation are required for neurodegeneration (Guttenplan et al., 2020).

\section{CROSSTALK BETWEEN MITOCHONDRIAL DYSFUNCTION AND INFLAMMATION}

Glaucoma is a complicated and progressive neurodegenerative disease where multiple pathways contribute to pathogenesis. Given that mitochondrial dysfunction and inflammation are two of the most potent influences, emerging evidence for interactions between these two factors has relevance for the etiology of glaucoma.

\section{MITOCHONDRIAL DYSFUNCTION CONTRIBUTES TO INFLAMMATION}

Mitochondrial dysfunction and inflammation are interdependent processes. Inhibition of Complex I by rotenone, or of Complex III by antimycin $\mathrm{A}$, in bone marrow-derived macrophages and in primary mouse microglia (Ferger et al., 2010) induced oxidative stress, activated microglia, activated the NLRP3 inflammasome, and increased IL- $1 \beta$ production, resulting in pyroptosis (Zhou et al., 2011). Rotenone administration concomitant with inhibition of autophagy caused the accumulation of damaged mitochondria with downstream IL-1 $\beta$ production (Nakahira et al., 2011; Zhou et al., 2011). Furthermore, subcutaneous injections of rotenone in rats increased IL-1 $\beta$ within the hypothalamus, confirming that mitochondria may act upstream of inflammation (Yi et al., 2007). Antioxidant treatment using sulforaphane (SFN) significantly prevented RGC death and suppressed microglia and inflammasome activation in the transient IOP $(110 \mathrm{mmHg}$ for $1 \mathrm{~h})$ model in 
rats suggesting that ROS production is upstream of inflammation (Gong et al., 2019). Collectively, studies indicate that mitochondria play an important role in regulating inflammation and that mitochondrial dysfunction is upstream of inflammation (Misawa et al., 2013); this has yet to be determined in glaucoma, however.

Mitochondrial dysfunction may contribute to various forms of inflammatory signaling, with links to NLRP3 inflammasome signaling of particular relevance for neurodegeneration (Nakahira et al., 2011; Zhou et al., 2011; Gurung et al., 2015). Many of these pathological links are related to excess levels of ROS; while ROS are mainly generated as byproducts of oxidative phosphorylation, excess production or inadequate removal of ROS can result in oxidative stress. Accumulated ROS results in the opening of the mitochondrial permeability transition pores that facilitates release of ROS (Kozlov et al., 2017) and damaged mtDNA (Shimada et al., 2012) into the cytoplasm; both substances act as DAMPs to induce NLRP3 inflammasome activation and pyroptosis (Latz et al., 2013; Yin et al., 2016; Bai et al., 2018). As ROS are short-lived and act only across short distances (Veal et al., 2007), positional shifts that recruit NLRP3 towards mitochondria enhance the ability of ROS to increase NLRP3 activation. During activation of the NLRP3 inflammasome, NLRP3 redistributes from the ER to mitochondria-associated ER membranes (MAMSs), where NLRP3 connects to the ASC adaptor protein, localized on the mitochondria, enabling inflammasome assembly (Green et al., 2011; Misawa et al., 2013; Heid et al., 2013; Misawa et al., 2013). Although the approximation of NLRP3-ASC at MAMs is important for NLRP3 activation, other factors also contribute. For example, the mitochondria-associated adaptor molecule, MAVS, is required for NLRP3 inflammasome activity as it promotes the recruitment of NLRP3 to the mitochondria and the subsequent IL-1 $\beta$ production in vivo (Subramanian et al., 2013), however, this has yet to be shown in glaucoma.

Mitochondrial dysfunction can also lead to increased inflammatory signaling through the cyclic GMP-AMP synthase (cGAS)-stimulator of interferon genes (STING) pathway (West and Shadel, 2017). The enzyme cGAS detects cytoplasmic DNA, including mtDNA leaked from damaged mitochondria. The reaction product cGAMP activates STING (Gao et al., 2013), which in turn stimulates TANK-binding kinase 1 (TBK1), to promote homodimerization of interferon regulatory factor 3 (IRF3) (Tanaka and Chen, 2012). Nuclear translocation of this phosphorylated IRF3 enhances expression of interferons and an enlarged interferon response (Hopfner and Hornung, 2020). mtDNA released across the plasma membrane can activate cGAS- or TLR9-dependent interferon signaling, thus communicating the mitochondrial damage to neighboring cells (West and Shadel, 2017). Components of the cGAS-STING pathway have been identified in the murine retina (Tang et al., 2019). In retinal microvascular endothelial cells, mtDNA in the cytosol stimulated the cGAS-STING pathway and nuclear translocation of IRF3 (Guo et al., 2020). Mutations in optineurin (OPTN) associated with primary open angle glaucoma $(\mathrm{E} 50 \mathrm{~K})$ reduced the phosphorylation of IRF3 and $\mathrm{IFN} \alpha / \beta$ release assays in response to poly (I:C) stimulation of
TLR3 (O'loughlin et al., 2020). Further investigations into the interactions between mtDNA releases as a result of mitochondrial dysfunction in glaucoma and the cGAS-STING-pathway promise to be informative.

Patients with glaucoma have an increased risk of developing Alzheimer's disease (Moon et al., 2018), and deposits of Alzheimer's disease marker amyloid beta $(\mathrm{A} \beta)$ accumulate in RGCs following IOP elevation (Guo et al., 2007), suggesting interactions between $A \beta$ and mitochondria may contribute to the pathology. $A \beta$ accumulation in mitochondrial cristae negatively impacted mitochondrial function. The translocase of the outer membrane (TOM) machinery moves $A \beta$ across the membrane, allowing it to accumulate (Petersen et al., 2008). Human neuroblastoma cells also internalized extracellularly applied $\mathrm{A} \beta$ that colocalized with mitochondrial markers (Petersen et al., 2008). While $A \beta$ accumulation has been shown in several glaucoma models (Mckinnon et al., 2002; Guo et al., 2007; Wilson et al., 2016), the accumulation of A $\beta$ in neuronal and glial mitochondria has yet to be shown in glaucoma as it has in the brain.

Mitochondrial dysfunction drives metabolic vulnerability in the D2 mouse ON and retina, which in turn triggers AMPactivated protein kinase activation (AMPK), a cellular energy sensor, to activate NF- $\mathrm{BB}$ signaling and increase expression of inflammatory genes (Harun-or-Rashid and Inman, 2018). Treatment with a ketogenic diet reduces inflammation, possibly while inhibiting AMPK activation while also meeting the high neuronal energy demand. Expression of AMPK was upregulated in the RGC of mice with elevated IOP following injection of magnetic microbeads (Belforte et al., 2018). Additional exploration of the role of AMPK in connecting mitochondrial damage with inflammation in glaucoma is likely to be fruitful, given the role of AMPK in systemic disease, and the therapeutic potential of manipulating this pathway in ocular disease (Powell et al., 2020).

\section{HYPOXIA CONTRIBUTES TO INFLAMMATION}

The NLRP3 inflammasome can also link hypoxia to inflammation and suggests how hypoxia, and thus increased IOP in glaucoma, can contribute to inflammation. Chronic intermittent hypoxia increased levels of cytokines associated with M1-and M2-like microglial activation states (Snyder et al., 2017). In retinal pigmented epithelial cells, hypoxia induced expression of NLRP3 and IL-1 $\beta$ in a pathway dependent upon ATP release and the P2Y12 receptor, and inflammasome activation killed cells only under hypoxic conditions (Doktor et al., 2018). HIF-1a is implicated in hypoxia-mediated inflammasome priming as blockage of HIF$1 \alpha$ reduced expression of NLRP3, caspase 1 and IL-1 $\beta$ and of pyroptotic death in a stroke model (Jiang et al., 2020).

Similar connections between hypoxia and inflammation may occur in glaucoma. IOP elevation and hypoxia can induce pyroptosis by activating CASP8; CASP8 triggered NF-kB translocation to induce HIF-1a signaling, which in turn 
facilitated NLRP12/NLRP3/NLRC4 assembly and activation in vitro and in vivo (Chen et al., 2020). Hypoxia also induces CASP1 release, NLRP3 inflammasome activation, IL-1 $\beta$ release, GSDMD cleavage, and pyroptosis (Watanabe et al., 2020). NLRP3 deficiency and CASP1 blockade significantly inhibited hypoxia-induced IL-1 $\beta$ release from macrophages. Indeed, genetic deletion of GSDMD, CASP8, or NLRP12 reduced RGC death after the transient IOP elevation model, where IOP was elevated to $110 \mathrm{mmHg}$ for $90 \mathrm{~min}$ (Chen et al., 2020).

Given that oxidative phosphorylation in the mitochondria is dependent on oxygen and is the main source of cellular ATP in addition to glycolysis, hypoxia and glucose deprivation decrease ATP, facilitate $\mathrm{K}^{+}$efflux, and induce IL- $1 \beta$ release. Interestingly, these effects were reversible by $\mathrm{K}^{+}$efflux inhibition and $\mathrm{K}_{\mathrm{ATP}}$ channel blockers in macrophages (Watanabe et al., 2020). The NLRP3 inflammasome acts as an intercellular sensor of ATP decrease induced by glucose and oxygen deprivation (Watanabe et al., 2020). Of relevance were studies showing that $\mathrm{K}_{\mathrm{ATP}}$ channel opener KR-31378 protected RGCs from ischemic damage (Bucolo et al., 2018). In retinal vessels activation of the $\mathrm{K}_{\mathrm{ATP}}$ channel dramatically increased the vasotoxicity of P2X7 receptor stimulation through elevation of calcium and increased oxidative stress (Shibata et al., 2018); such interactions may increase hypoxic challenge in glaucoma given the propensity of excess P2X7 receptor stimulation with elevated IOP (Mitchell et al., 2008). Further studies will be necessary to elucidate the precise link between the $\mathrm{K}_{\mathrm{ATP}}$ channel, the P2X7 receptor, NLRP3 inflammasome activation and cellular metabolic crisis in glia vs. neurons during glaucoma.

There is also considerable evidence of a role for carbon monoxide in glaucoma (Bucolo and Drago, 2011). A carbon monoxide-releasing molecule, CORM-3, produced a dosedependent reduction in IOP in the rabbit eye (Stagni et al., 2009). The precise mechanism remains to be determined, although action on $\mathrm{KCa}^{2+}$ channels in the outflow pathway has been suggested (Dong et al., 2007; Bucolo and Drago, 2011). Recent work in a model of hind limb ischemia suggests the stabilization of HIF-1 $\alpha$ by hemeoxygenase 1 (Hmoxl) is at least partially attributed to carbon monoxide, with carbon monoxide a by-product of the breakdown of heme by of Hmox1 (Dunn et al., 2021). In addition, carbon monoxide regulates mitochondrial biogenesis and gene expression, suggesting multiple protective sites in glaucoma are possible (Cherry and Piantadosi, 2015).

\section{DYSFUNCTIONAL MITOPHAGY EXACERBATES INFLAMMATION}

Mitophagy helps regulate mitochondria homeostasis by getting rid of dysfunctional mitochondria, and the inhibition of mitophagy results in the accumulation of damaged mitochondria and sometimes inflammasome activation. Mitophagy is driven by PTEN-induced putative kinase 1 (PINK1) and parkin (E3 ubiquitin ligase), where the cytoplasmic Parkin is recruited to the mitochondria to interact with PINK1 on the outer mitochondrial membrane and target dysfunctional mitochondria (Palikaras et al., 2018). Adaptor proteins such as p62 and OPTN join poly-ubiquitinated strands to light chain 3 (LC3), initiating autophagy. The mitochondrial accumulation of LC3 puncta after treatment with Complex I inhibitor rotenone indicate mitophagy is increased by mitochondrial stress (Zhou et al., 2011).

Impaired mitophagy has been implicated in glaucoma by multiple observations. Elevation of IOP in rats increased damaged mitochondria, parkin and optineurin levels in RGCs, while function was partially restored following overexpression of Parkin (Dai et al., 2018). Impaired mitophagy was also implicated in the myelinated ON axons of D2 mice by a rise in fragmented and damaged mitochondria without changes in PINK or parkin levels (Coughlin et al., 2015). These mice also displayed increased mitochondria within autophagosomes in distal and proximal axons (Kleesattel et al., 2015). An autosomal dominant form of normal tension glaucoma is linked to mutations in OPTN (Rezaie et al., 2002), and mice transgenic for E50K, the most common mutation in normal tension glaucoma, showed altered mitophagy and mitochondrial fission (Shim et al., 2016). Pink1 and Parkin KO mice both showed an increase in increased inflammation, but antioxidants abolished CASP1 activation, suggesting a role for ROS in the inflammation associated with impaired mitophagy (Sliter et al., 2018). These findings emphasize the importance of mitophagy in combating inflammation, and justify further examination in glaucoma.

NLRP3 inflammasome activation is negatively regulated by mitophagy (Latz et al., 2013; Lai et al., 2018). Autophagic proteins contribute to an anti-inflammatory response by regulating NLRP3 inflammation and mitochondrial integrity (Nakahira et al., 2011). Inflammasome activation recruits autophagy adaptor protein p62 to the mitochondria. Measuring LC3 and p62 puncta is a method of quantifying autophagy/ mitophagy. LC3 and p62 enable mitophagy, thereby inhibiting NLRP3 inflammasome activation and preventing excessive IL-1 $\beta$ production by degrading damaged mitochondria in macrophages (Zhong et al., 2016). Depletion of genes for autophagic proteins (specifically LC3B and Beclin 1), and the use of mitophagy inhibitors (such as 3-methyladenine), promoted CASP1 activation, secretion of IL-1 $\beta$ and IL-18, and the accumulation of dysfunctional mitochondria in macrophages and in vivo (Nakahira et al., 2011). In addition, stimulation by lipopolysaccharide (LPS) or ATP led to the release of mtDNA and ROS into the cytosol and inflammasomedependent secretion of IL-1 $\beta$ and IL-18 (Nakahira et al., 2011).

Mitophagy can limit apoptosis by reducing the accumulation of dysfunctional mitochondrial and oxidative stress, and facilitate the metabolic switch of the cell from oxidative phosphorylation to glycolysis to adapt to the hypoxia reported during glaucoma (Liu et al., 2012a; Jassim and Inman, 2019). Hypoxia-induced mitophagy occurs through the action of a mitochondrial associated membrane protein, FUNDC1, as reported in vitro (Liu et al., 2012a; Chen et al., 2016; Wu et al., 2016). During hypoxia, oxidative phosphorylation is expected to decline and glycolysis would become the primary ATP source in the 


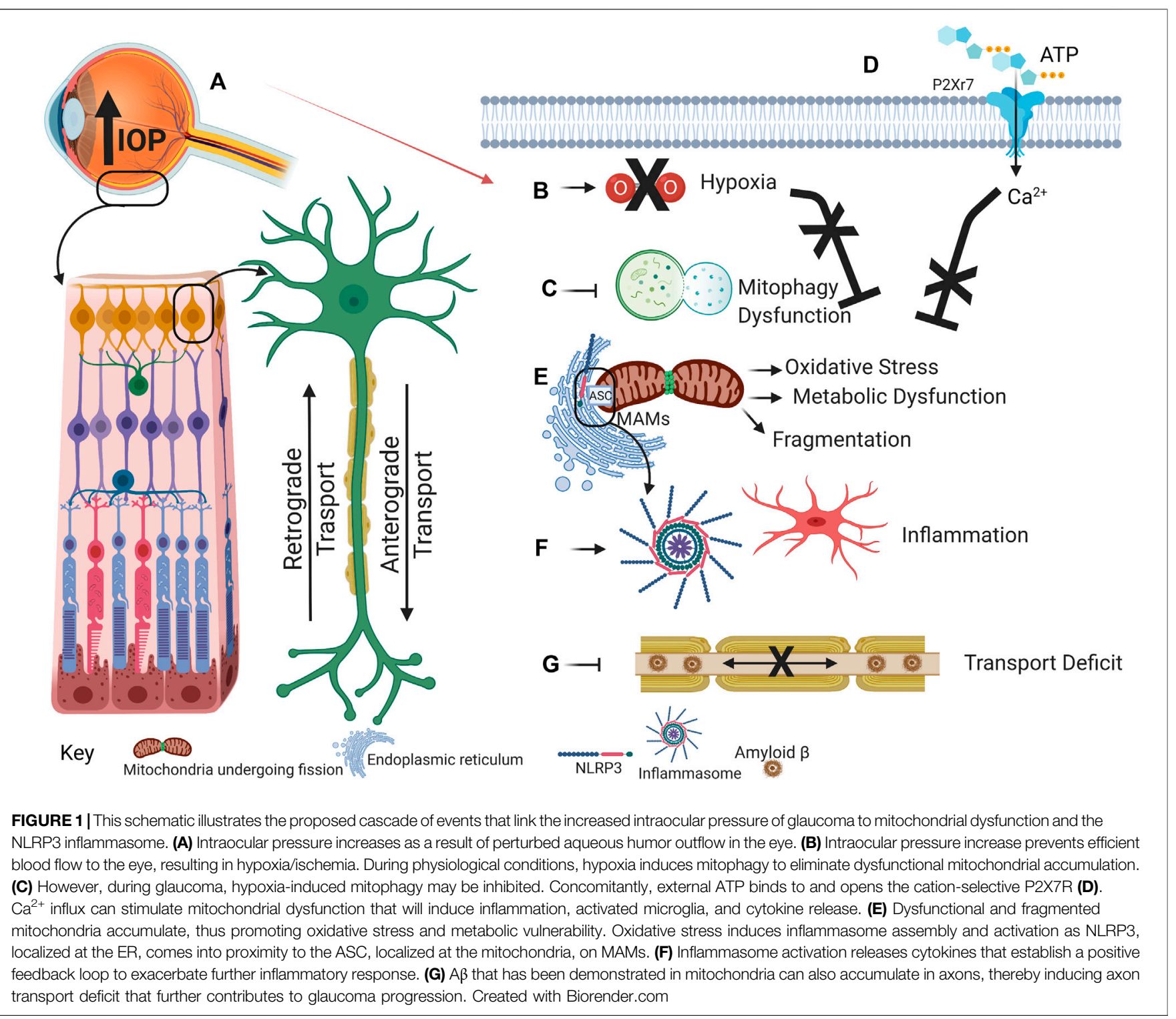

TABLE 1 | Pharmacological targets to ameliorate mitochondrial dysfunction and inflammation.

\begin{tabular}{|c|c|c|c|c|}
\hline $\begin{array}{l}\text { Protein/ } \\
\text { Gene }\end{array}$ & $\begin{array}{c}\text { Biological } \\
\text { target }\end{array}$ & Targeted pathway & Scientific evidence & References \\
\hline
\end{tabular}

\begin{tabular}{|c|c|c|c|c|}
\hline HIF-1a & Nucleus & Hypoxic response & Hypoxia preconditioniong rescue RGC during glaucoma & Gidday et al. (2015) \\
\hline $\begin{array}{l}\text { KATP } \\
\text { channel }\end{array}$ & Membrane & Metabolic function & $\begin{array}{l}\mathrm{K}_{\text {ATP }} \text { blockers reduced IL- } 1 \beta \text { release; } \mathrm{K}_{\text {ATP }} \text { opener protected } \\
\text { RGCs from ischemic damage }\end{array}$ & Watanabe et al. (2020) \\
\hline HCAR1 & Mitochondria & L-lactate receptor & $\begin{array}{l}\text { Ketogenic diet stimulates HCAR1 to inhibit NLRP3 } \\
\text { inflammasome in glaucoma }\end{array}$ & $\begin{array}{l}\text { Harun-or-Rashid and Inman, } \\
\text { (2018) }\end{array}$ \\
\hline AMPK & Cytosol & Energy sensor protein kinase & $\begin{array}{l}\text { Ketogenic diet reduced metabolic vulnerability and AMPK- } \\
\text { induceds inflammation }\end{array}$ & $\begin{array}{l}\text { Harun-or-Rashid and Inman, } \\
\text { (2018) }\end{array}$ \\
\hline cGAS & $\begin{array}{l}\text { Interferon in } \\
\text { cytosol }\end{array}$ & STING pathway & Detects leaked mtDNA & Sintim et al. (2019) \\
\hline$A \beta$ & $\begin{array}{l}\text { Cytosol, } \\
\text { mitochondria }\end{array}$ & $\begin{array}{l}\text { Biomarker of neurodegeneration, } \\
\text { impaired clearance }\end{array}$ & $\begin{array}{l}\text { Accumulates in mitochondria cristae, blocks function; induces } \\
\text { pro-inflamatory cytokines via P2X7R }\end{array}$ & $\begin{array}{l}\text { Chiozzi et al., 2019, Petersen } \\
\text { et al., } 2008\end{array}$ \\
\hline
\end{tabular}


cell. Although high reliance on glycolysis was recently shown in glaucomatous D2 ON (Jassim et al., 2021), degeneration proceeds, indicating that ATP produced from glycolysis is insufficient to meet the high energy demand of axons during glaucoma.

\section{INFLAMMATION CAN INDUCE MITOCHONDRIAL DYSFUNCTION}

While there is considerable evidence suggesting that dysfunctional mitochondria can trigger inflammation, the opposite is also true, with inflammation inducing mitochondrial dysfunction. Inflammasome assembly can impair organelle function and integrity; for example, activation of the NLRP3 inflammasome in macrophages reduced cytoplasmic levels of ATP and mitochondrial function (Heid et al., 2013). Inflammation in LPS-treated macrophages resulted in a metabolic shift from oxidative phosphorylation to glycolysis (Mills et al., 2016). Interestingly, Complex II and Complex I oxidation, and decreased $\mathrm{NAD}^{+}$were necessary for the proinflammatory response observed in these macrophages. TNFa induced a oxidative phosphorylation deficit in a mouse hippocampal cell line, suggesting a detrimental impact of inflammation on mitochondrial function (Doll et al., 2015). In optic nerve head astrocytes, stimulation of TLR3 led to a transfer of cellular ATP from cytoplasmic to extracellular compartments, suggesting inflammatory signaling can strain cellular energetics in relationship to glaucoma (Beckel et al., 2018).

Microglia metabolic reprogramming has been found in response to inflammation as cells switch between oxidative phosphorylation and glycolytic metabolism (Lauro and Limatola, 2020). Activated microglia have dysfunctional mitochondria and they switch to glycolysis to compensate for ATP loss. Stimulation of microglial cells with LPS reduced mitochondrial oxygen consumption, ATP production and oxidative phosphorylation, while increasing glycolysis (Voloboueva et al., 2013). In addition, mitochondrial dysfunction in microglia propagates mitochondrial dysfunction in neurons and can block some of the alternative response triggered by IL-4 (Ferger et al., 2010). As this IL-4 response can reduce inflammation, mitochondrial dysfunction might contribute to the pathological changes found in activated microglia in glaucoma. Whether inflammatory stimuli lead microglia in the retina to switch from oxidative

\section{REFERENCES}

Albalawi, F., Lu, W., Beckel, J. M., Lim, J. C., Mccaughey, S. A., and Mitchell, C. H. (2017). The P2X7 Receptor Primes IL-1 $\beta$ and the NLRP3 Inflammasome in Astrocytes Exposed to Mechanical Strain. Front Cel Neurosci 11, 227. doi:10.3389/fncel.2017.00227

Allard, B., Longhi, M. S., Robson, S. C., and Stagg, J. (2017). The Ectonucleotidases CD39 and CD73: Novel Checkpoint Inhibitor Targets. Immunol. Rev. 276, 121-144. doi:10.1111/imr.12528

Bai, H., Yang, B., Yu, W., Xiao, Y., Yu, D., and Zhang, Q. (2018). Cathepsin B Links Oxidative Stress to the Activation of NLRP3 Inflammasome. Exp. Cel Res. 362, 180-187. doi:10.1016/j.yexcr.2017.11.015 phosphorylation to glycolysis should be investigated given central role of microglia in glaucomatous pathogenesis.

\section{DISCUSSION AND FUTURE DIRECTIONS}

The strong support for mitochondrial dysfunction and inflammation in glaucoma outlined above, combined with growing evidence for crosstalk between mitochondrial dysfunction and inflammation in other neurodegenerations, suggests interaction between these processes contributes to the expanding pathogenesis in glaucoma patients. We propose that IOP elevation initiates hypoxia that contributes to mitochondrial dysfunction, oxidative stress, impaired mitophagy and inflammation and that these processes are exacerbated by interactions between inflammation and mitochondrial dysfunctional (Figure 1).

While expanding evidence for both inflammation and mitochondrial dysfunction supports crosstalk, the degree of interaction may be influenced by several key factors, and suggests several key targets for intervention (Table 1). For example, the microglial activation state is expected to have a considerable impact on waste accumulation and impaired mitophagy (Campagno and Mitchell, 2021). Investigations into compartmentalized interaction between ASC, NLRP3 and oxidative stress in soma, axon, and synapse has particular relevance for glaucoma given the ganglion cell architecture. The ability of inflammation to disrupt mitochondrial signaling remains largely undetermined in glaucoma. The development of in vitro models using neurons, astrocytes, and microglia, in addition to the use and development of mouse glaucoma models with knockout technologies, will enable us to resolve these questions.

\section{AUTHOR CONTRIBUTIONS}

CHM, DMI, and AHJ conceived, outlined, and wrote the review.

\section{FUNDING}

This work was supported by R01 EY013434 (CHM) R01 EY015537 (CHM) R01 EY026662 (DMI) and T32NS043126 (AHJ).

Baltan, S., Inman, D. M., Danilov, C. A., Morrison, R. S., Calkins, D. J., and Horner, P. J. (2010). Metabolic Vulnerability Disposes Retinal Ganglion Cell Axons to Dysfunction in a Model of Glaucomatous Degeneration. J. Neurosci. 30, 5644-5652. doi:10.1523/jneurosci.5956-09.2010

Bartlett, R., Yerbury, J. J., and Sluyter, R. (2013). P2X7 Receptor Activation Induces Reactive Oxygen Species Formation and Cell Death in Murine EOC13 Microglia. Mediators Inflamm. 2013, 271813. doi:10.1155/2013/271813

Beckel, J. M., Argall, A. J., Lim, J. C., Xia, J., Lu, W., Coffey, E. E., et al. (2014). Mechanosensitive Release of Adenosine $5^{\prime}$-triphosphate through Pannexin Channels and Mechanosensitive Upregulation of Pannexin Channels in Optic Nerve Head Astrocytes: A Mechanism for Purinergic Involvement in Chronic Strain. Glia 62, 1486-1501. doi:10.1002/glia.22695 
Beckel, J. M., Gomez, N. M., Lu, W., Campagno, K. E., Nabet, B., Albalawi, F., et al. (2018). Stimulation of TLR3 Triggers Release of Lysosomal ATP in Astrocytes and Epithelial Cells that Requires TRPML1 Channels. Sci. Rep. 8, 5726. doi:10.1038/s41598-018-23877-3

Belforte, N., Vargas, J. L. C., and Polo, A. D. (2018). Metabolic Stress in Glaucoma Engages Early Activation of the Energy Biosensor Adenosine MonophosphateActivated Protein Kinase Leading to Neuronal Dysfunction. Ann. Eye Sci. 3.AB015

Bell, K., Und Hohenstein-Blaul, N. V T., Teister, J., and Grus, F. (2018). Modulation of the Immune System for the Treatment of Glaucoma. Cn 16, 942-958. doi:10.2174/1570159x15666170720094529

Bolaños, J. P., Almeida, A., and Moncada, S. (2010). Glycolysis: a Bioenergetic or a Survival Pathway? Trends Biochem. Sci. 35, 145-149. doi:10.1016/j.tibs.2009.10.006

Bosco, A., Crish, S. D., Steele, M. R., Romero, C. O., Inman, D. M., Horner, P. J., et al. (2012). Early Reduction of Microglia Activation by Irradiation in a Model of Chronic Glaucoma. PLoS One 7. doi:10.1371/journal.pone.0043602

Bosco, A., Inman, D. M., Steele, M. R., Wu, G., Soto, I., Marsh-Armstrong, N., et al. (2008). Reduced Retina Microglial Activation and Improved Optic Nerve Integrity with Minocycline Treatment in the DBA/2J Mouse Model of Glaucoma. Invest. Ophthalmol. Vis. Sci. 49, 1437-1446. doi:10.1167/iovs.071337

Bosco, A., Romero, C. O., Breen, K. T., Chagovetz, A. A., Steele, M. R., Ambati, B. K., et al. (2015). Neurodegeneration Severity Can Be Predicted from Early Microglia Alterations Monitored In Vivo in a Mouse Model of Chronic Glaucoma. Dis. Model. Mech. 8, 443-455. doi:10.1242/dmm.018788

Bosco, A., Steele, M. R., and Vetter, M. L. (2011). Early Microglia Activation in a Mouse Model of Chronic Glaucoma. J. Comp. Neurol. 519, 599-620. doi:10.1002/cne.22516

Bucolo, C., and Drago, F. (2011). Carbon Monoxide and the Eye: Implications for Glaucoma Therapy. Pharmacol. Ther. 130, 191-201. doi:10.1016/ j.pharmthera.2011.01.013

Bucolo, C., Leggio, G. M., Maltese, A., Castorina, A., D’Agata, V., Drago, F., et al. (2012). Dopamine-3 Receptor Modulates Intraocular Pressure: Implications for Glaucoma. Biochem. Pharmacol. 83, 680-686. doi:10.1016/j.bcp.2011.11.031

Bucolo, C., Platania, C. B. M., Drago, F., Bonfiglio, V., Reibaldi, M., Avitabile, T., et al. (2018). Novel Therapeutics in Glaucoma Management. Cn 16, 978-992. doi:10.2174/1570159x15666170915142727

Calkins, D. J. (2012). Critical Pathogenic Events Underlying Progression of Neurodegeneration in Glaucoma. Prog. Retin. Eye Res. 31, 702-719. doi:10.1016/j.preteyeres.2012.07.001

Campagno, K. E., and Mitchell, C. H. (2021). The P2X7 Receptor in Microglial Cells Modulates the Endolysosomal axis, Autophagy and Phagocytosis. Front. Cell Neurosci. 15, 66. doi:10.3389/fncel.2021.645244

Chandel, N. S., Maltepe, E., Goldwasser, E., Mathieu, C., Simon, M., and Schumacker, P. (1998). Mitochondrial Reactive Oxygen Species Trigger Hypoxia- Induced Transcription. PNAS 95.

Chandel, N. S., Mcclintock, D. S., Feliciano, C. E., Wood, T. M., Melendez, J. A., Rodriguez, A. M., et al. (2000). Reactive Oxygen Species Generated at Mitochondrial Complex III Stabilize Hypoxia-Inducible Factor-1 1 during Hypoxia. J. Biol. Chem. 275, 25130-25138. doi:10.1074/jbc.m001914200

Chandra, D., Liu, J.-W., and Tang, D. G. (2002). Early Mitochondrial Activation and Cytochrome C Up-Regulation during Apoptosis. J. Biol. Chem. 277, 50842-50854. doi:10.1074/jbc.m207622200

Chen, H., Deng, Y., Gan, X., Li, Y., Huang, W., Lu, L., et al. (2020). NLRP12 Collaborates with NLRP3 and NLRC4 to Promote Pyroptosis Inducing Ganglion Cell Death of Acute Glaucoma. Mol. Neurodegener 15, 26. doi:10.1186/s13024-020-00372-w

Chen, M., Chen, Z., Wang, Y., Tan, Z., Zhu, C., Li, Y., et al. (2016). Mitophagy Receptor FUNDC1 Regulates Mitochondrial Dynamics and Mitophagy. Autophagy 12, 689-702. doi:10.1080/15548627.2016.1151580

Chen, Z., and Trapp, B. D. (2016). Microglia and Neuroprotection. J. Neurochem. 136 (136 Suppl. 1), 10-17. doi:10.1111/jnc.13062

Cherry, A. D., and Piantadosi, C. A. (2015). Regulation of Mitochondrial Biogenesis and its Intersection with Inflammatory Responses. Antioxid. Redox Signaling 22, 965-976. doi:10.1089/ars.2014.6200

Chi, W., Li, F., Chen, H., Wang, Y., Zhu, Y., Yang, X., et al. (2014). Caspase-8 Promotes NLRP1/NLRP3 Inflammasome Activation and IL-1 Production in
Acute Glaucoma. Proc. Natl. Acad. Sci. 111, 11181-11186. doi:10.1073/ pnas. 1402819111

Chiozzi, P., Sarti, A. C., Sanz, J. M., Giuliani, A. L., Adinolfi, E., Vultaggio-Poma, V., et al. (2019). Amyloid $\beta$-dependent Mitochondrial Toxicity in Mouse Microglia Requires P2X7 Receptor Expression and Is Prevented by Nimodipine. Scientific Rep. 9, 6475. doi:10.1038/s41598-019-42931-2

Coughlin, L., Morrison, R. S., Horner, P. J., and Inman, D. M. (2015). Mitochondrial Morphology Differences and Mitophagy Deficit in Murine Glaucomatous Optic Nerve. Invest. Ophthalmol. Vis. Sci. 56, 1437-1446. doi:10.1167/iovs.14-16126

Cserép, C., Pósfai, B., Lénárt, N., Fekete, R., László, Z. I., Lele, Z., et al. (2020). Microglia Monitor and Protect Neuronal Function through Specialized Somatic Purinergic Junctions. Science 367, 528-537. doi:10.1126/science.aax6752

Cwerman-Thibault, H., Lechauve, C., Augustin, S., Roussel, D., Reboussin, É., Mohammad, A., et al. (2017). Neuroglobin Can Prevent or Reverse Glaucomatous Progression in DBA/2J Mice. Mol. Ther. - Methods Clin. Development 5, 200-220. doi:10.1016/j.omtm.2017.04.008

Dai, C., Khaw, P. T., Yin, Z. Q., Li, D., Raisman, G., and Li, Y. (2012). Structural Basis of Glaucoma: the Fortified Astrocytes of the Optic Nerve Head Are the Target of Raised Intraocular Pressure. Glia 60, 13-28. doi:10.1002/glia.21242

Dai, Y., Hu, X., and Sun, X. (2018). Overexpression of Parkin Protects Retinal Ganglion Cells in Experimental Glaucoma. Cell Death Dis 9, 88. doi:10.1038/ s41419-017-0146-9

De Moraes, C. G., Liebmann, J. M., and Levin, L. A. (2017). Detection and Measurement of Clinically Meaningful Visual Field Progression in Clinical Trials for Glaucoma. Prog. Retin. Eye Res. 56, 107-147. doi:10.1016/ j.preteyeres.2016.10.001

Dengler-Crish, C. M., Smith, M. A., Inman, D. M., Wilson, G. N., Young, J. W., and Crish, S. D. (2014). Anterograde Transport Blockade Precedes Deficits in Retrograde Transport in the Visual Projection of the DBA/2J Mouse Model of Glaucoma. Front. Neurosci. 8, 290. doi:10.3389/fnins.2014.00290

Doktor, F., Prager, P., Wiedemann, P., Kohen, L., Bringmann, A., and Hollborn, M. (2018). Hypoxic Expression of NLRP3 and VEGF in Cultured Retinal Pigment Epithelial Cells: Contribution of P2Y2 Receptor Signaling. Purinergic Signal. 14, 471-484. doi:10.1007/s11302-018-9631-6

Doll, D. N., Rellick, S. L., Barr, T. L., Ren, X., and Simpkins, J. W. (2015). Rapid Mitochondrial Dysfunction Mediates TNF-Alpha-Induced Neurotoxicity. J. Neurochem. 132, 443-451. doi:10.1111/jnc.13008

Dong, D.-L., Zhang, Y., Lin, D.-H., Chen, J., Patschan, S., Goligorsky, M. S., et al. (2007). Carbon Monoxide Stimulates the Ca2+-Activated Big Conductance K Channels in Cultured Human Endothelial Cells. Hypertension 50, 643-651. doi:10.1161/hypertensionaha.107.096057

Dunn, L. L., Kong, S. M. Y., Tumanov, S., Chen, W., Cantley, J., Ayer, A., et al. (2021). Hmox1 (Heme Oxygenase-1) Protects against Ischemia-Mediated Injury via Stabilization of HIF-1 $\alpha$ (Hypoxia-Inducible Factor-1 $\alpha$ ). Arteriosclerosis, Thromb. Vasc. Biol. 41, 317-330.

Ferger, A. I., Campanelli, L., Reimer, V., Muth, K. N., Merdian, I., Ludolph, A. C., et al. (2010). Effects of Mitochondrial Dysfunction on the Immunological Properties of Microglia. J. Neuroinflammation 7, 45. doi:10.1186/1742-20947-45

Fernandes, K. A., Harder, J. M., Williams, P. A., Rausch, R. L., Kiernan, A. E., Nair, K. S., et al. (2015). Using Genetic Mouse Models to Gain Insight into Glaucoma: Past Results and Future Possibilities. Exp. Eye Res. 141, 42-56. doi:10.1016/ j.exer.2015.06.019

Frenzel, M., Rommelspacher, H., Sugawa, M. D., and Dencher, N. A. (2010). Ageing Alters the Supramolecular Architecture of OxPhos Complexes in Rat Brain Cortex. Exp. Gerontol. 45, 563-572. doi:10.1016/j.exger.2010.02.003

Gao, D., Wu, J., Wu, Y.-T., Du, F., Aroh, C., Yan, N., et al. (2013). Cyclic GMPAMP Synthase Is an Innate Immune Sensor of HIV and Other Retroviruses. Science 341, 903-906. doi:10.1126/science.1240933

García-Bermúdez, M. Y., Freude, K. K., Mouhammad, Z. A., Van Wijngaarden, P., Martin, K. K., and Kolko, M.. (2021). Glial Cells in Glaucoma: Friends, Foes, and Potential Therapeutic Targets. Front. Neurol. 12, 624983. doi:10.3389/ fneur.2021.624983

Gerometta, R., Podos, S. M., Candia, O. A., Wu, B., Malgor, L. A., Mittag, T., et al. (2004). Steroid-induced Ocular Hypertension in normal Cattle. Arch. Ophthalmol. 122, 1492-1497. doi:10.1001/archopht.122.10.1492 
Ghosh, A. K., Rao, V. R., Wisniewski, V. J., Zigrossi, A. D., Floss, J., Koulen, P., et al. (2020). Differential Activation of Glioprotective Intracellular Signaling Pathways in Primary Optic Nerve Head Astrocytes after Treatment with Different Classes of Antioxidants. Antioxid. (Basel) 9.

Gidday, J. M., Zhang, L., Chiang, C.-W., and Zhu, Y. (2015). Enhanced Retinal Ganglion Cell Survival in Glaucoma by Hypoxic Postconditioning after Disease Onset. Neurotherapeutics 12, 502-514. doi:10.1007/s13311-014-0330-x

Gombault, A., Baron, L., and Couillin, I. (2012). ATP Release and Purinergic Signaling in NLRP3 Inflammasome Activation. Front. Immunol. 3, 414. doi:10.3389/fimmu.2012.00414

Gong, Y., Cao, X., Gong, L., and Li, W. (2019). Sulforaphane Alleviates Retinal Ganglion Cell Death and Inflammation by Suppressing NLRP3 Inflammasome Activation in a Rat Model of Retinal Ischemia/reperfusion Injury. Int. J. Immunopathol Pharmacol. 33, 2058738419861777. doi:10.1177/ 2058738419861777

Green, D. R., Galluzzi, L., and Kroemer, G. (2011). Mitochondria and the Autophagy-Inflammation-Cell Death axis in Organismal Aging. Science 333, 1109-1112. doi:10.1126/science.1201940

Guo, H., Callaway, J. B., and Ting, J. P.-Y. (2015). Inflammasomes: Mechanism of Action, Role in Disease, and Therapeutics. Nat. Med. 21, 677-687. doi:10.1038/ nm.3893

Guo, L., Salt, T. E., Luong, V., Wood, N., Cheung, W., Maass, A., et al. (2007). Targeting Amyloid-Beta in Glaucoma Treatment. Proc. Natl. Acad. Sci. 104, 13444-13449. doi:10.1073/pnas.0703707104

Guo, Y., Gu, R., Gan, D., Hu, F., Li, G., and Xu, G. (2020). Mitochondrial DNA Drives Noncanonical Inflammation Activation via cGAS-STING Signaling Pathway in Retinal Microvascular Endothelial Cells. Cell Commun. Signaling 18, 172. doi:10.1186/s12964-020-00637-3

Gurung, P., Lukens, J. R., and Kanneganti, T.-D. (2015). Mitochondria: Diversity in the Regulation of the NLRP3 Inflammasome. Trends Mol. Med. 21, 193-201. doi:10.1016/j.molmed.2014.11.008

Guttenplan, K. A., Stafford, B. K., El-Danaf, R. N., Adler, D. I., Münch, A. E., Weigel, M. K., et al. (2020). Neurotoxic Reactive Astrocytes Drive Neuronal Death after Retinal Injury. Cel Rep. 31, 107776. doi:10.1016/j.celrep.2020.107776

Hamanaka, R. B., and Chandel, N. S. (2009). Mitochondrial Reactive Oxygen Species Regulate Hypoxic Signaling. Curr. Opin. Cel Biol. 21, 894-899. doi:10.1016/j.ceb.2009.08.005

Harun-or-Rashid, M., Pappenhagen, N., Zubricky, R., Coughlin, L., Jassim, A. H., and Inman, D. M. (2020). MCT2 Overexpression Rescues Metabolic Vulnerability and Protects Retinal Ganglion Cells in Two Models of Glaucoma. Neurobiol. Dis., 141, 104944. doi:10.1016/j.nbd.2020.104944

Harun-or-Rashid, M., and Inman, D. M. (2018). Reduced AMPK Activation and Increased HCAR Activation Drive Anti-inflammatory Response and Neuroprotection in Glaucoma. J. Neuroinflammation 15, 313. doi:10.1186/ s12974-018-1346-7

Harun-or-Rashid, M., Pappenhagen, N., Palmer, P. G., Smith, M. A., Gevorgyan, V., Wilson, G. N., et al. (2018). Structural and Functional Rescue of Chronic Metabolically Stressed Optic Nerves through Respiration. J. Neurosci. 38, 5122-5139. doi:10.1523/jneurosci.3652-17.2018

Hayakawa, K., Esposito, E., Wang, X., Terasaki, Y., Liu, Y., Xing, C., et al. (2016). Transfer of Mitochondria from Astrocytes to Neurons after Stroke. Nature 535, 551-555. doi:10.1038/nature18928

Heid, M. E., Keyel, P. A., Kamga, C., Shiva, S., Watkins, S. C., and Salter, R. D. (2013). Mitochondrial Reactive Oxygen Species Induces NLRP3-dependent Lysosomal Damage and Inflammasome Activation. J.I. 191, 5230-5238. doi:10.4049/jimmunol.1301490

Heneka, M. T., Kummer, M. P., Stutz, A., Delekate, A., Schwartz, S., VieiraSaecker, A., et al. (2013). NLRP3 Is Activated in Alzheimer's Disease and Contributes to Pathology in APP/PS1 Mice. Nature 493, 674-678. doi:10.1038/nature11729

Herrero-Mendez, A., Almeida, A., Fernández, E., Maestre, C., Moncada, S., and Bolaños, J. P. (2009). The Bioenergetic and Antioxidant Status of Neurons Is Controlled by Continuous Degradation of a Key Glycolytic Enzyme by APC/ C-Cdh1. Nat. Cel Biol 11, 747-752. doi:10.1038/ncb1881

Hickman, S. E., Allison, E. K., and El Khoury, J. (2008). Microglial Dysfunction and Defective -Amyloid Clearance Pathways in Aging Alzheimer's Disease Mice. J. Neurosci. 28, 8354-8360. doi:10.1523/jneurosci.0616-08.2008
Himori, N., Yamamoto, K., Maruyama, K., Ryu, M., Taguchi, K., Yamamoto, M., et al. (2013). Critical Role of Nrf2 in Oxidative Stress-Induced Retinal Ganglion Cell Death. J. Neurochem. 127, 669-680. doi:10.1111/jnc.12325

Hopfner, K.-P., and Hornung, V. (2020). Molecular Mechanisms and Cellular Functions of cGAS-STING Signalling. Nat. Rev. Mol. Cel Biol 21, 501-521. doi:10.1038/s41580-020-0244-x

Howell, G. R., Macalinao, D. G., Sousa, G. L., Walden, M., Soto, I., Kneeland, S. C., et al. (2011). Molecular Clustering Identifies Complement and Endothelin Induction as Early Events in a Mouse Model of Glaucoma. J. Clin. Invest. 121, 1429-1444. doi:10.1172/jci44646

Inman, D. M., and Harun-or-Rashid, M. (2017). Metabolic Vulnerability in the Neurodegenerative Disease Glaucoma. Front. Neurosci. 11, 146. doi:10.3389/ fnins.2017.00146

Inman, D. M., Sappington, R. M., Horner, P. J., and Calkins, D. J. (2006). Quantitative Correlation of Optic Nerve Pathology with Ocular Pressure and Corneal Thickness in the DBA/2 Mouse Model of Glaucoma. Invest. Ophthalmol. Vis. Sci. 47, 986-996. doi:10.1167/iovs.05-0925

Jassim, A. H. C. L., Coughlin, M., Kang, P. T., Chen, Y.-R., and Inman, D. M. (2019). Higher Reliance on Glycolysis Limits Glycolytic Responsiveness in Degenerating Glaucomatous Optic Nerve. Mol. Neurobiol. 56, 7097-7112. doi:10.1007/s12035-019-1576-4

Jassim, A. H., Fan, Y., Pappenhagen, N., Nsiah, N. Y., and Inman, D. M. (2021). Oxidative Stress and Hypoxia Modifies Mitochondrial Homeostasis during Glaucoma. Antioxid. Redox Signal. [Epub ahead of print]. doi:10.1089/ ars.2020.8180

Jassim, and Inman (2019). Evidence of Hypoxic Glial Cells in a Model of Ocular Hypertension. Invest. Ophthalmol. Vis. Sci. 60, 1-15.

Jiang, Q., Geng, X., Warren, J., Eugene Paul Cosky, E., Kaura, S., Stone, C., et al. (2020). Hypoxia Inducible Factor-1a (HIF-1a) Mediates NLRP3 Inflammasome-Dependent-Pyroptotic and Apoptotic Cell Death Following Ischemic Stroke. Neuroscience 448, 126-139. doi:10.1016/ j.neuroscience.2020.09.036

Jo, E.-K., Kim, J. K., Shin, D.-M., and Sasakawa, C. (2016). Molecular Mechanisms Regulating NLRP3 Inflammasome Activation. Cell Mol Immunol 13, 148-159. doi:10.1038/cmi.2015.95

Josef, F., Selim Orgul, V. P. C., Orzalesi, Nicola., GuNterKrieglstein, K., and Serra, Luis. Metzner. (2002). J.-P.R., Einar Stefa!NssonThe Impact of Ocular Blood Flow in Glaucoma. Prog. Retin. Eye Res. 21, 359-393.

Joshi, A. U., Minhas, P. S., Liddelow, S. A., Haileselassie, B., Andreasson, K. I., Dorn, G. W., 2nd, et al. (2019). Fragmented Mitochondria Released from Microglia Trigger A1 Astrocytic Response and Propagate Inflammatory Neurodegeneration. Nat. Neurosci. 22, 1635-1648. doi:10.1038/s41593-0190486-0

Kamat, S. S., Gregory, M. S., and Pasquale, L. R. (2016). The Role of the Immune System in Glaucoma: Bridging the Divide between Immune Mechanisms in Experimental Glaucoma and the Human Disease. Semin. Ophthalmol. 31, 147-154. doi:10.3109/08820538.2015.1114858

Kamel, K., Farrell, M., and O'brien, C. (2017). Mitochondrial Dysfunction in Ocular Disease: Focus on Glaucoma. Mitochondrion 35, 44-53. doi:10.1016/ j.mito.2017.05.004

Kleesattel, D., Crish, S. D., and Inman, D. M. (2015). Decreased Energy Capacity and Increased Autophagic Activity in Optic Nerve Axons with Defective Anterograde Transport. Invest. Ophthalmol. Vis. Sci. 56, 8215-8227. doi:10.1167/iovs.15-17885

Koizumi, S., Ohsawa, K., Inoue, K., and Kohsaka, S. (2013). Purinergic Receptors in Microglia: Functional Modal Shifts of Microglia Mediated by P2 and P1 Receptors. Glia 61, 47-54. doi:10.1002/glia.22358

Kong, G. Y. X., Van Bergen, N. J., Trounce, I. A., and Crowston, J. G. (2009). Mitochondrial Dysfunction and Glaucoma. J. Glaucoma 18, 93-100. doi:10.1097/ijg.0b013e318181284f

Kozlov, A. V., Lancaster, J. R., Jr., Meszaros, A. T., and Weidinger, A. (2017). Mitochondria-meditated Pathways of Organ Failure upon Inflammation. Redox Biol. 13, 170-181. doi:10.1016/j.redox.2017.05.017

Lai, M., Yao, H., Shah, S. Z. A., Wu, W., Wang, D., Zhao, Y., et al. (2018). The NLRP3-Caspase 1 Inflammasome Negatively Regulates Autophagy via TLR4TRIF in Prion Peptide-Infected Microglia. Front. Aging Neurosci. 10, 116. doi:10.3389/fnagi.2018.00116 
Lannes, N., Eppler, E., Etemad, S., Yotovski, P., and Filgueira, L. (2017). Microglia at center Stage: a Comprehensive Review about the Versatile and Unique Residential Macrophages of the central Nervous System. Oncotarget 8, 114393-114413. doi:10.18632/oncotarget.23106

Latz, E., Xiao, T. S., and Stutz, A. (2013). Activation and Regulation of the Inflammasomes. Nat. Rev. Immunol. 13, 397-411. doi:10.1038/ nri3452

Lauro, C., and Limatola, C. (2020). Metabolic Reprograming of Microglia in the Regulation of the Innate Inflammatory Response. Front. Immunol. 11, 493. doi:10.3389/fimmu.2020.00493

Leadsham, J. E., Sanders, G., Giannaki, S., Bastow, E. L., Hutton, R., Naeimi, W. R., et al. (2013). Loss of Cytochrome C Oxidase Promotes RAS-dependent ROS Production from the ER Resident NADPH Oxidase, Ynolp, in Yeast. Cel Metab. 18, 279-286. doi:10.1016/j.cmet.2013.07.005

Lee, S., Van Bergen, N. J., Kong, G. Y., Chrysostomou, V., Waugh, H. S., O’Neill, E. C., et al. (2011). Mitochondrial Dysfunction in Glaucoma and Emerging Bioenergetic Therapies. Exp. Eye Res. 93, 204-212. doi:10.1016/ j.exer.2010.07.015

Li, A., Zhang, X., Zheng, D., Ge, J., Laties, A. M., and Mitchell, C. H. (2011). Sustained Elevation of Extracellular ATP in Aqueous Humor from Humans with Primary Chronic Angle-Closure Glaucoma. Exp. Eye Res. 93, 528-533. doi:10.1016/j.exer.2011.06.020

Libby, R. T., Anderson, M. G., Pang, I.-H., Robinson, Z. H., Savinova, O. V., Cosma, I. M., et al. (2005). Inherited Glaucoma in DBA/2J Mice: Pertinent Disease Features for Studying the Neurodegeneration. Vis. Neurosci. 22, 637-648. doi:10.1017/s0952523805225130

Liddelow, S. A., Guttenplan, K. A., Clarke, L. E., Bennett, F. C., Bohlen, C. J., Schirmer, L., et al. (2017). Neurotoxic Reactive Astrocytes Are Induced by Activated Microglia. Nature 541, 481-487. doi:10.1038/nature21029

Lim, J. C., Lu, W., Beckel, J. M., and Mitchell, C. H. (2016). Neuronal Release of Cytokine IL-3 Triggered by Mechanosensitive Autostimulation of the P2X7 Receptor Is Neuroprotective. Front. Cel Neurosci 10, 270. doi:10.3389/ fncel.2016.00270

Liu, L., Feng, D., Chen, G., Chen, M., Zheng, Q., Song, P., et al. (2012a). Mitochondrial Outer-Membrane Protein FUNDC1 Mediates HypoxiaInduced Mitophagy in Mammalian Cells. Nat. Cel Biol 14, 177-185. doi: $10.1038 / \mathrm{ncb} 2422$

Liu, X., Zhang, Z., Ruan, J., Pan, Y., Magupalli, V. G., Wu, H., et al. (2016). Inflammasome-activated Gasdermin D Causes Pyroptosis by Forming Membrane Pores. Nature 535, 153-158. doi:10.1038/nature18629

Lu, W., Albalawi, F., Beckel, J. M., Lim, J. C., Laties, A. M., and Mitchell, C. H. (2017). The P2X7 Receptor Links Mechanical Strain to Cytokine IL-6 UpRegulation and Release in Neurons and Astrocytes. J. Neurochem. 141, 436-448. doi:10.1111/jnc. 13998

Lu, W., Hu, H., Sévigny, J., Gabelt, B. A. T., Kaufman, P. L., Johnson, E. C., et al. (2015). Rat, Mouse, and Primate Models of Chronic Glaucoma Show Sustained Elevation of Extracellular ATP and Altered Purinergic Signaling in the Posterior Eye. Invest. Ophthalmol. Vis. Sci. 56, 3075-3083. doi:10.1167/iovs.14-15891

Mac Nair, C. E., and Nickells, R. W. (2015). Neuroinflammation in Glaucoma and Optic Nerve Damage. Prog. Mol. Biol. Transl Sci. 134, 343-363. doi:10.1016/ bs.pmbts.2015.06.010

Madry, C., Kyrargyri, V., Arancibia-Cárcamo, I. L., Jolivet, R., Kohsaka, S., Bryan, R. M., et al. (2018). Microglial Ramification, Surveillance, and Interleukin-1 $\beta$ Release Are Regulated by the Two-Pore Domain K+ Channel THIK-1. Neuron 97, 299-312. doi:10.1016/j.neuron.2017.12.002

Mahesh, N., Maher, S., and Vittorio, P. (2007). IOP-dependent Retinal Ganglion Cell Dysfunction in Glaucomatous DBA/2J Mice. Invest. Ophthalmol. Vis. Sci. 48, 4573-4579.

Mckinnon, S. J., Lehman, D. M., Kerrigan-Baumrind, L. A., Merges, C. A., Pease, M. E., Kerrigan, D. F., et al. (2002). Caspase Activation and Amyloid Precursor Protein Cleavage in Rat Ocular Hypertension. Invest. Ophthalmol. Vis. Sci. 43, 1077-1087.

Mills, E. L., Kelly, B., Logan, A., Costa, A. S. H., Varma, M., Bryant, C. E., et al. (2016). Succinate Dehydrogenase Supports Metabolic Repurposing of Mitochondria to Drive Inflammatory Macrophages. Cell 167, 457-470. doi:10.1016/j.cell.2016.08.064
Misawa, T., Takahama, M., Kozaki, T., Lee, H., Zou, J., Saitoh, T., et al. (2013). Microtubule-driven Spatial Arrangement of Mitochondria Promotes Activation of the NLRP3 Inflammasome. Nat. Immunol. 14, 454-460. doi:10.1038/ni.2550

Mitchell, C. H., Lu, W., Hu, H., Zhang, X., Reigada, D., and Zhang, M. (2008). The P2X7 Receptor in Retinal Ganglion Cells: A Neuronal Model of PressureInduced Damage and protection by a Shifting Purinergic Balance. Purinergic Signal. 4, 313-321. doi:10.1007/s11302-008-9125-z

Moon, J. Y., Kim, H. J., Park, Y. H., Park, T. K., Park, E. C., Kim, C. Y., et al. (2018). Association between Open-Angle Glaucoma and the Risks of Alzheimer's and Parkinson's Diseases in South Korea: A 10-year Nationwide Cohort Study. Sci. Rep. 8, 11161. doi:10.1038/s41598-018-29557-6

Morzaev, D., Nicholson, J. D., Caspi, T., Weiss, S., Hochhauser, E., and Goldenberg-Cohen, N. (2015). Toll-like Receptor-4 Knockout Mice Are More Resistant to Optic Nerve Crush Damage Than Wild-type Mice. Clin. Exp. Ophthalmol 43, 655-665. doi:10.1111/ceo.12521

Munemasa, Y., Kitaoka, Y., Kuribayashi, J., and Ueno, S. (2010). Modulation of Mitochondria in the Axon and Soma of Retinal Ganglion Cells in a Rat Glaucoma Model. J. Neurochem. 115, 1508-1519. doi:10.1111/j.14714159.2010.07057.x

Munoz, F. M., Gao, R., Tian, Y., Henstenburg, B. A., Barrett, J. E., and Hu, H. (2017). Neuronal P2X7 Receptor-Induced Reactive Oxygen Species Production Contributes to Nociceptive Behavior in Mice. Scientific Rep. 7, 3539. doi:10.1038/s41598-017-03813-7

Murphy, M. P. (2013). Mitochondrial Dysfunction Indirectly Elevates ROS Production by the Endoplasmic Reticulum. Cel Metab. 18, 145-146. doi:10.1016/j.cmet.2013.07.006

Nakahira, K., Haspel, J. A., Rathinam, V. A. K., Lee, S.-J., Dolinay, T., Lam, H. C., et al. (2011). Autophagy Proteins Regulate Innate Immune Responses by Inhibiting the Release of Mitochondrial DNA Mediated by the NALP3 Inflammasome. Nat. Immunol. 12, 222-230. doi:10.1038/ni.1980

Nita, M., and Grzybowski, A. (2016). The Role of the Reactive Oxygen Species and Oxidative Stress in the Pathomechanism of the Age-Related Ocular Diseases and Other Pathologies of the Anterior and Posterior Eye Segments in Adults. Oxidative Med. Cell. longevity 2016, 3164734. doi:10.1155/2016/ 3164734

O'loughlin, T., Kruppa, A. J., Ribeiro, A. L. R., Edgar, J. R., Ghannam, A., Smith, A. M., et al. (2020). OPTN Recruitment to a Golgi-Proximal Compartment Regulates Immune Signalling and Cytokine Secretion. J. Cel Sci. 133. doi: $10.1242 /$ jcs. 239822

Oikawa, K., Ver Hoeve, J. N., Teixeira, L. B. C., Snyder, K. C., Kiland, J. A., Ellinwood, N. M., et al. (2020). Sub-region-Specific Optic Nerve Head Glial Activation in Glaucoma. Mol. Neurobiol. 57, 2620-2638. doi:10.1007/s12035020-01910-9

Overby, D. R., and Clark, A. F. (2015). Animal Models of Glucocorticoid-Induced Glaucoma. Exp. Eye Res. 141, 15-22. doi:10.1016/j.exer.2015.06.002

Palikaras, K., Lionaki, E., and Tavernarakis, N. (2018). Mechanisms of Mitophagy in Cellular Homeostasis, Physiology and Pathology. Nat. Cel Biol 20, 1013-1022. doi:10.1038/s41556-018-0176-2

Panchal, S. S., Patidar, R. K., Jha, A. B., Allam, A. A., Ajarem, J., and Butani, S. B. (2017). Anti-Inflammatory and Antioxidative Stress Effects of Oryzanol in Glaucomatous Rabbits. J. Ophthalmol. 2017, 1468716. doi:10.1155/2017/ 1468716

Pang, I.-H., and Clark, A. F. (2020). Inducible Rodent Models of Glaucoma. Prog. Retin. Eye Res. 75, 100799. doi:10.1016/j.preteyeres.2019.100799

Petersen, C. A. H., Alikhani, N., Behbahani, H., Wiehager, B., Pavlov, P. F., Alafuzoff, I., et al. (2008). The Amyloid Beta-Peptide Is Imported into Mitochondria via the TOM Import Machinery and Localized to Mitochondrial Cristae. Proc. Natl. Acad. Sci. U S A. 105, 13145-13150. doi:10.1073/pnas.0806192105

Platania, C. B., Di Paola, L., Leggio, G. M., Romano, G. L., Drago, F., Salomone, S., et al. (2015). Molecular Features of Interaction between VEGFA and Antiangiogenic Drugs Used in Retinal Diseases: a Computational Approach. Front. Pharmacol. 6, 248. doi:10.3389/fphar.2015.00248

Platania, C. B. M., Leggio, G. M., Drago, F., Salomone, S., and Bucolo, C. (2013). Regulation of Intraocular Pressure in Mice: Structural Analysis of Dopaminergic and Serotonergic Systems in Response to Cabergoline. Biochem. Pharmacol. 86, 1347-1356. doi:10.1016/j.bcp.2013.08.010 
Powell, S., Irnaten, M., and Brien, C. J.. (2020). A Review of Metabolic Sensors in Glaucoma. Trends Ophthalmol. 3.

Pronin, A., Pham, D., An, W., Dvoriantchikova, G., Reshetnikova, G., Qiao, J., et al. (2019). Inflammasome Activation Induces Pyroptosis in the Retina Exposed to Ocular Hypertension Injury. Front. Mol. Neurosci. 12, 36. doi:10.3389/ fnmol.2019.00036

Puyang, Z., Feng, L., Chen, H., Liang, P., Troy, J. B., and Liu, X. (2016). Retinal Ganglion Cell Loss Is Delayed Following Optic Nerve Crush in NLRP3 Knockout Mice. Sci. Rep. 6, 20998. doi:10.1038/srep20998

Reigada, D., Lu, W., Zhang, M., and Mitchell, C. H. (2008). Elevated Pressure Triggers a Physiological Release of ATP from the Retina: Possible Role for Pannexin Hemichannels. Neuroscience 157, 396-404. doi:10.1016/ j.neuroscience.2008.08.036

Reigada, D., Lu, W., Zhang, X., Friedman, C., Pendrak, K., Mcglinn, A., et al. (2005). Degradation of Extracellular ATP by the Retinal Pigment Epithelium. Am. J. Physiology-Cell Physiol. 289, C617-C624. doi:10.1152/ ajpcell.00542.2004

Rezaie, T., Child, A., Hitchings, R., Brice, G., Miller, L., Coca-Prados, M., et al. (2002). Adult-onset Primary Open-Angle Glaucoma Caused by Mutations in Optineurin. Science 295, 1077-1079. doi:10.1126/science.1066901

Rieck, J. (2013). The Pathogenesis of Glaucoma in the Interplay with the Immune System. Invest. Ophthalmol. Vis. Sci. 54, 2393-2409. doi:10.1167/iovs.12-9781

Rodríguez-Gómez, J. A., Kavanagh, E., Engskog-Vlachos, P., Engskog, M. K. R., Herrera, A. J., Espinosa-Oliva, A. M., et al. (2020). Agents of the CNS Proinflammatory Response. Cells 9.

Rojas, B., Gallego, B. I., Ramírez, A. I., Salazar, J. J., De Hoz, R., Valiente-Soriano, F. J., et al. (2014). Microglia in Mouse Retina Contralateral to Experimental Glaucoma Exhibit Multiple Signs of Activation in All Retinal Layers. J. neuroinflammation 11, 133. doi:10.1186/1742-2094-11-133

Romano, G. L., Amato, R., Lazzara, F., Porciatti, V., Chou, T.-H., Drago, F., et al. (2020). P2X7 Receptor Antagonism Preserves Retinal Ganglion Cells in Glaucomatous Mice. Biochem. Pharmacol. 180, 114199. doi:10.1016/ j.bcp.2020.114199

Russo, R., Varano, G. P., Adornetto, A., Nucci, C., Corasaniti, M. T., Bagetta, G., et al. (2016). Retinal Ganglion Cell Death in Glaucoma: Exploring the Role of Neuroinflammation. Eur. J. Pharmacol. 787, 134-142. doi:10.1016/ j.ejphar.2016.03.064

Samsel, P. A., Kisiswa, L., Erichsen, J. T., Cross, S. D., and Morgan, J. E. (2011). A Novel Method for the Induction of Experimental Glaucoma Using Magnetic Microspheres. Invest. Ophthalmol. Vis. Sci. 52, 1671-1675. doi:10.1167/iovs.093921

Sanderson, J., Dartt, D. A., Trinkaus-Randall, V., Pintor, J., Civan, M. M., Delamere, N. A., et al. (2014). Purines in the Eye: Recent Evidence for the Physiological and Pathological Role of Purines in the RPE, Retinal Neurons, Astrocytes, Müller Cells, Lens, Trabecular Meshwork, Cornea and Lacrimal Gland. Exp. Eye Res. 127, 270-279. doi:10.1016/j.exer.2014.08.009

Sappington, R. M., Carlson, B. J., Crish, S. D., and Calkins, D. J. (2010). The Microbead Occlusion Model: a Paradigm for Induced Ocular Hypertension in Rats and Mice. Invest. Ophthalmol. Vis. Sci. 51, 207-216. doi:10.1167/iovs.093947

Shibata, M., Ishizaki, E., Zhang, T., Fukumoto, M., Barajas-Espinosa, A., Li, T., et al. (2018). Role of the Pore/Oxidant/K(ATP) Channel/Ca(2+) Pathway in P2X(7)Induced Cell Death in Retinal Capillaries. Vision (Basel) 2.

Shih, A. Y., Johnson, D. A., Wong, G., Kraft, A. D., Jiang, L., Erb, H., et al. (2003). Coordinate Regulation of Glutathione Biosynthesis and Release by Nrf2Expressing Glia Potently Protects Neurons from Oxidative Stress. J. Neurosci. 23, 3394-3406. doi:10.1523/jneurosci.23-08-03394.2003

Shim, M. S., Takihara, Y., Kim, K. Y., Iwata, T., Yue, B. Y., Inatani, M., et al. (2016). Mitochondrial Pathogenic Mechanism and Degradation in Optineurin E50K Mutation-Mediated Retinal Ganglion Cell Degeneration. Sci. Rep. 6, 33830. doi:10.1038/srep33830

Shimada, K., Crother, T. R., Karlin, J., Dagvadorj, J., Chiba, N., Chen, S., et al. (2012). Oxidized Mitochondrial DNA Activates the NLRP3 Inflammasome during Apoptosis. Immunity 36, 401-414. doi:10.1016/j.immuni.2012.01.009

Sintim, H. O., Mikek, C. G., Wang, M., and Sooreshjani, M. A. (2019). Interrupting Cyclic Dinucleotide-cGAS-STING axis with Small Molecules. Med. Chem. Commun. 10, 1999-2023. doi:10.1039/c8md00555a
Slabaugh, M., and Salim, S. (2017). Use of Anti-VEGF Agents in Glaucoma Surgery. J. Ophthalmol. 2017, 1645269. doi:10.1155/2017/1645269

Sliter, D. A., Martinez, J., Hao, L., Chen, X., Sun, N., Fischer, T. D., et al. (2018). Parkin and PINK1 Mitigate STING-Induced Inflammation. Nature 561, 258-262. doi:10.1038/s41586-018-0448-9

Snyder, B., Shell, B., Cunningham, J. T., and Cunningham, R. L. (2017). Chronic Intermittent Hypoxia Induces Oxidative Stress and Inflammation in Brain Regions Associated with Early-Stage Neurodegeneration. Physiol. Rep. 5, e13258. doi:10.14814/phy2.13258

Son, J. L., Soto, I., Oglesby, E., Lopez-Roca, T., Pease, M. E., Quigley, H. A., et al. (2010). Glaucomatous Optic Nerve Injury Involves Early Astrocyte Reactivity and Late Oligodendrocyte Loss. Glia 58, 780-789. doi:10.1002/ glia.20962

Stagni, E., Privitera, M. G., Bucolo, C., Leggio, G. M., Motterlini, R., and Drago, F. (2009). A Water-Soluble Carbon Monoxide-Releasing Molecule (CORM-3) Lowers Intraocular Pressure in Rabbits. Br. J. Ophthalmol. 93, 254-257. doi:10.1136/bjo.2007.137034

Sterling, J. K., Adetunji, M. O., Guttha, S., Bargoud, A. R., Uyhazi, K. E., Ross, A. G., et al. (2020). GLP-1 Receptor Agonist NLY01 Reduces Retinal Inflammation and Neuron Death Secondary to Ocular Hypertension. Cel Rep. 33, 108271. doi:10.1016/j.celrep.2020.108271

Stowell, C., Burgoyne, C. F., Tamm, E. R., Ethier, C. R., Dowling, J. E., Downs, C., et al. (2017). Biomechanical Aspects of Axonal Damage in Glaucoma: A Brief Review. Exp. Eye Res. 157, 13-19. doi:10.1016/j.exer.2017.02.005

Subramanian, N., Natarajan, K., Clatworthy, M. R., Wang, Z., and Germain, R. N. (2013). The Adaptor MAVS Promotes NLRP3 Mitochondrial Localization and Inflammasome Activation. Cell 153, 348-361. doi:10.1016/j.cell.2013.02.054

Swanson, K. V., Deng, M., and Ting, J. P.-Y. (2019). The NLRP3 Inflammasome: Molecular Activation and Regulation to Therapeutics. Nat. Rev. Immunol. 19, 477-489. doi:10.1038/s41577-019-0165-0

Takai, Y., Tanito, M., and Ohira, A. (2012). Multiplex Cytokine Analysis of Aqueous Humor in Eyes with Primary Open-Angle Glaucoma, Exfoliation Glaucoma, and Cataract. Invest. Ophthalmol. Vis. Sci. 53, 241-247. doi:10.1167/ iovs.11-8434

Tamm, E. R., Ethier, C. R., Dowling, J. E., Downs, C., Ellisman, M. H., Fisher, S., et al. (2017). Biological Aspects of Axonal Damage in Glaucoma: A Brief Review. Exp. Eye Res. 157, 5-12. doi:10.1016/j.exer.2017.02.006

Tanaka, Y., and Chen, Z. J. (2012). STING Specifies IRF3 Phosphorylation by TBK1 in the Cytosolic DNA Signaling Pathway. Sci. Signal. 5, ra20. doi:10.1126/ scisignal.2002521

Tang, M., Pavlou, S., Chen, M., and Xu, H. (2019). cGAS-STING Pathway Activation in Murine Retina. Acta Ophthalmologica 97.

Tezel, G. (2006). Oxidative Stress in Glaucomatous Neurodegeneration: Mechanisms and Consequences. Prog. Retin. Eye Res. 25, 490-513. doi:10.1016/j.preteyeres.2006.07.003

Tezel, G. (2011). The Immune Response in Glaucoma: a Perspective on the Roles of Oxidative Stress. Exp. Eye Res. 93, 178-186. doi:10.1016/ j.exer.2010.07.009

Tham, Y.-C., Li, X., Wong, T. Y., Quigley, H. A., Aung, T., and Cheng, C.-Y. (2014). Global Prevalence of Glaucoma and Projections of Glaucoma Burden through 2040. Ophthalmology 121, 2081-2090. doi:10.1016/j.ophtha.2014.05.013

Tribble, J. R., Vasalauskaite, A., Redmond, T., Young, R. D., Hassan, S., Fautsch, M. P., et al. (2019). Midget Retinal Ganglion Cell Dendritic and Mitochondrial Degeneration Is an Early Feature of Human Glaucoma. Brain Commun. 1, fcz035.

Veal, E. A., Day, A. M., and Morgan, B. A. (2007). Hydrogen Peroxide Sensing and Signaling. Mol. Cel 26, 1-14. doi:10.1016/j.molcel.2007.03.016

Venegas, C., Kumar, S., Franklin, B. S., Dierkes, T., Brinkschulte, R., Tejera, D., et al. (2017). Microglia-derived ASC Specks Cross-Seed Amyloid- $\beta$ in Alzheimer's Disease. Nature 552, 355-361. doi:10.1038/nature25158

Ventura, A. L. M., Dos Santos-Rodrigues, A., Mitchell, C. H., and Faillace, M. P. (2019). Purinergic Signaling in the Retina: From Development to Disease. Brain Res. Bull. 151, 92-108. doi:10.1016/j.brainresbull.2018.10.016

Voloboueva, L. A., Emery, J. F., Sun, X., and Giffard, R. G. (2013). Inflammatory Response of Microglial BV-2 Cells Includes a Glycolytic Shift and Is Modulated by Mitochondrial Glucose-Regulated Protein 75/mortalin. FEBS Lett. 587, 756-762. doi:10.1016/j.febslet.2013.01.067 
Wang, Y., Chen, S., Liu, Y., Huang, W., Li, X., and Zhang, X. (2018). Inflammatory Cytokine Profiles in Eyes with Primary Angle-Closure Glaucoma. Biosci. Rep. 38.

Watanabe, S., Usui-Kawanishi, F., Karasawa, T., Kimura, H., Kamata, R., Komada, T., et al. (2020). Glucose Regulates Hypoxia-Induced NLRP3 Inflammasome Activation in Macrophages. J. Cel Physiol.

Wax, M. B., Tezel, G., Yang, J., Peng, G., Patil, R. V., Agarwal, N., et al. (2008). Induced Autoimmunity to Heat Shock Proteins Elicits Glaucomatous Loss of Retinal Ganglion Cell Neurons via Activated T-Cell-Derived Fas-Ligand. J. Neurosci. 28, 12085-12096. doi:10.1523/jneurosci.3200-08.2008

Wei, X., Cho, K.-S., Thee, E. F., Jager, M. J., and Chen, D. F. (2019). Neuroinflammation and Microglia in Glaucoma: Time for a Paradigm Shift. J. Neuro Res. 97, 70-76. doi:10.1002/jnr.24256

West, A. P., and Shadel, G. S. (2017). Mitochondrial DNA in Innate Immune Responses and Inflammatory Pathology. Nat. Rev. Immunol. 17, 363-375. doi:10.1038/nri.2017.21

Whitlock, N. A., Mcknight, B., Corcoran, K. N., Rodriguez, L. A., and Rice, D. S. (2010). Increased Intraocular Pressure in Mice Treated with Dexamethasone. Invest. Ophthalmol. Vis. Sci. 51, 6496-6503. doi:10.1167/iovs.10-5430

Whitmore, A. V., Libby, R. T., and John, S. W. M. (2005). Glaucoma: Thinking in New Ways-A Rôle for Autonomous Axonal Self-Destruction and Other Compartmentalised Processes? Prog. Retin. Eye Res. 24, 639-662. doi:10.1016/j.preteyeres.2005.04.004

Williams, P. A., Harder, J. M., Foxworth, N. E., Cochran, K. E., Philip, V. M., Porciatti, V., et al. (2017). Vitamin B3modulates Mitochondrial Vulnerability and Prevents Glaucoma in Aged Mice. Science 355, 756-760. doi:10.1126/ science.aal0092

Wilson, G. N., Inman, D. M., Dengler Crish, C. M., Smith, M. A., and Crish, S. D. (2015). Early Pro-inflammatory Cytokine Elevations in the DBA/2J Mouse Model of Glaucoma. J. Neuroinflammation 12, 176. doi:10.1186/s12974-0150399-0

Wilson, G. N., Smith, M. A., Inman, D. M., Dengler-Crish, C. M., and Crish, S. D. (2016). Early Cytoskeletal Protein Modifications Precede Overt Structural Degeneration in the DBA/2J Mouse Model of Glaucoma. Front. Neurosci. 10, 494. doi:10.3389/fnins.2016.00494

Wu, J.-h., Zhang, S.-h., Nickerson, J. M., Gao, F.-j., Sun, Z., Chen, X.-y., et al. (2015). Cumulative mtDNA Damage and Mutations Contribute to the Progressive Loss of RGCs in a Rat Model of Glaucoma. Neurobiol. Dis. 74, 167-179. doi:10.1016/j.nbd.2014.11.014

Wu, W., Li, W., Chen, H., Jiang, L., Zhu, R., and Feng, D. (2016). FUNDC1 Is a Novel Mitochondrial-Associated-Membrane (MAM) Protein Required for Hypoxia-Induced Mitochondrial Fission and Mitophagy. Autophagy 12, 1675-1676. doi:10.1080/15548627.2016.1193656

Yang, Q., Cho, K.-S., Chen, H., Yu, D., Wang, W.-H., Luo, G., et al. (2012). Microbead-induced Ocular Hypertensive Mouse Model for
Screening and Testing of Aqueous Production Suppressants for Glaucoma. Invest. Ophthalmol. Vis. Sci. 53, 3733-3741. doi:10.1167/ iovs.12-9814

Yang, X., Hondur, G., and Tezel, G. (2016). Antioxidant Treatment Limits Neuroinflammation in Experimental Glaucoma. Invest. Ophthalmol. Vis. Sci. 57, 2344-2354. doi:10.1167/iovs.16-19153

Yang, X., Luo, C., Cai, J., Powell, D. W., Yu, D., Kuehn, M. H., et al. (2011). Neurodegenerative and Inflammatory Pathway Components Linked to TNF-A/ tnfr1 Signaling in the Glaucomatous Human Retina. Invest. Ophthalmol. Vis. Sci. 52, 8442-8454. doi:10.1167/iovs.11-8152

Yerramothu, P., Vijay, A. K., and Willcox, M. D. P. (2018). Inflammasomes, the Eye and Anti-inflammasome Therapy. Eye 32, 491-505. doi:10.1038/ eye.2017.241

Yi, P.-L., Tsai, C.-H., Lu, M.-K., Liu, H.-J., Chen, Y.-C., and Chang, F.-C. (2007). Interleukin-1 $\beta$ Mediates Sleep Alteration in Rats with Rotenone-Induced Parkinsonism. Sleep 30, 413-425. doi:10.1093/sleep/30.4.413

Yin, F., Sancheti, H., Patil, I., and Cadenas, E. (2016). Energy Metabolism and Inflammation in Brain Aging and Alzheimer's Disease. Free Radic. Biol. Med. 100, 108-122. doi:10.1016/j.freeradbiomed.2016.04.200

Yuan, L., and Neufeld, A. H. (2001). Activated Microglia in the Human Glaucomatous Optic Nerve Head. J. Neurosci. Res. 64, 523-532. doi:10.1002/jnr.1104

Zhang, X., Li, A., Ge, J., Reigada, D., Laties, A. M., and Mitchell, C. H. (2007). Acute Increase of Intraocular Pressure Releases ATP into the Anterior Chamber. Exp. Eye Res. 85, 637-643. doi:10.1016/j.exer.2007.07.016

Zheng, D., Liwinski, T., and Elinav, E. (2020). Inflammasome Activation and Regulation: toward a Better Understanding of Complex Mechanisms. Cel Discov. 6, 36. doi:10.1038/s41421-020-0167-x

Zhong, Z., Umemura, A., Sanchez-Lopez, E., Liang, S., Shalapour, S., Wong, J., et al. (2016). NF- $\mathrm{kB}$ Restricts Inflammasome Activation via Elimination of Damaged Mitochondria. Cell 164, 896-910. doi:10.1016/j.cell.2015.12.057

Zhou, R., Yazdi, A. S., Menu, P., and Tschopp, J. (2011). A Role for Mitochondria in NLRP3 Inflammasome Activation. Nature 469, 221-225. doi:10.1038/nature09663

Conflict of Interest: The authors declare that the research was conducted in the absence of any commercial or financial relationships that could be construed as a potential conflict of interest.

Copyright (c) 2021 Jassim, Inman and Mitchell. This is an open-access article distributed under the terms of the Creative Commons Attribution License (CC $B Y)$. The use, distribution or reproduction in other forums is permitted, provided the original author(s) and the copyright owner(s) are credited and that the original publication in this journal is cited, in accordance with accepted academic practice. No use, distribution or reproduction is permitted which does not comply with these terms. 